\title{
Shake Table Tests of a Novel Low-rise Bolt- Assembled Precast Concrete Sandwich Wall Panel Structure
}

\section{Feng Xiong}

Sichuan University - Wangjiang Campus: Sichuan University

\section{Wen Chen}

Sichuan University - Wangjiang Campus: Sichuan University

Qi Ge ( $\sim$ geqi@scu.edu.cn )

Sichuan University - Wangjiang Campus: Sichuan University

\section{Jiang Chen}

Sichuan University - Wangjiang Campus: Sichuan University

\section{Yang Lu}

Sichuan University - Wangjiang Campus: Sichuan University

\section{Research Article}

Keywords: shake table test, precast concrete sandwich wall panel structure, demountable bolt connection, seismic performance, Low-rise

Posted Date: January 4th, 2022

DOI: https://doi.org/10.21203/rs.3.rs-1212295/v1

License: (1) This work is licensed under a Creative Commons Attribution 4.0 International License. Read Full License 


\title{
Shake Table Tests of a Novel Low-rise Bolt-Assembled Precast Concrete Sandwich Wall Panel Structure 1
}

\author{
Feng Xiong ${ }^{\# 1}$, Wen Chen ${ }^{\# 1,2}$, Qi Ge*1, Jiang Chen ${ }^{1}$, Yang Lu ${ }^{1}$ \\ ${ }^{1}$ MOE Key laboratory of Deep Earth Science and Engineering, College of Architecture and Environment, Sichuan \\ University, Chengdu 610065, China \\ ${ }^{2}$ School of Environment and Resource, Southwest University of Science and Technology, Mianyang 621010, China
}

\begin{abstract}
A novel low-rise bolt - assembled precast concrete sandwich wall panel structure for rural residential houses was proposed, in which the connections between wall and wall, and wall and floor were connected by high strength bolts and steel plates. The bolt joints can be easily installed and disassembled. They are replaceable to make the precast structure demountable and reassembled. All the components are connected together by the novel bolted connectors. This paper presents the shake-table tests of a full-scale two-story bolt-assembled precast concrete sandwich wall building. The results indicated that the proposed structural system had good seismic performance and remained in the elastic stage with no damage after 9-degree rare earthquake excitation for the Model-1. The Model-2 exhibited excellent capacity and performed satisfactorily under the excitation up to $0.8 \mathrm{~g}$. Cracks were observed at the wall openings and the base of walls and columns, which was similar to that of a cast-in-situ structure. The damage statuses were mainly light damage and moderate damage. The bolt connection joints were not anti-seismic weak places and had good seismic performance. Equivalent base shear method is suitable for estimating the seismic demand of the proposed precast concrete sandwich wall panel structure.
\end{abstract}

Keywords: shake table test; precast concrete sandwich wall panel structure; demountable bolt connection; seismic performance; Low-rise;

\section{Introduction}

The precast concrete sandwich wall panel offers a high degree of industrialization for a building and is an important developing direction for precast reinforced concrete structures. With promoting building and housing industrialization currently in China, the precast concrete wall structure is developed as an alternative to these old residential buildings in rural areas. The row-rise residential building is generally the main demand in the rural areas of China. The precast concrete sandwich wall (PCSW) is very suitable for the low-rise residential building due to its advantages of low cost, rapid construction, high stiffness and good thermal insulation performance.

According to different connection types, the precast concrete wall panel structural system can be classified into the monolithic wall system and the jointed wall system. In the monolithic construction, precast concrete components are joined by post-cast concrete in the reserved areas. These connections make the wall system have an equivalent behaviour with conventional cast-in-situ concrete structure. During the past decade, the monolithic wall system has been studied using the experimental and analytical methods by a number of researchers [1-5]. These researches have shown that the monolithic wall system have excellent seismic performance, and the structural integrity can be guaranteed. However, the key issue of these wet connections in the monolithic system is that the complicated construction process reduces the construction speed, which vastly weakens the advantages of the precast concrete structure.

In an effort to enhance the efficiency in the monolithic system, the jointed wall systems were proposed, which used dry joints (i.e. bolting, welding or post-tensioned tendons) to connect precast members or components, requiring no concrete to be casted at the site. In this manner, all the components in the jointed wall system can even be completely disassembled to repair or reuse. Several kinds of post-tensioned precast concrete wall systems has been experimentally and theoretically investigated in the last decades [6-12] and they exhibited excellent performance with only minor damage and self-centering capability. However, because of the expensive cost by using post-tensioning tendons and various energy dissipation connectors, these post-tensioned precast concrete wall systems have not been widely implemented in China, particularly in the vast rural areas.

Recently, the bolt-assembled wall system was received with more attention. According to different deformation forms of bolts, the bolted connectors can generally be categorised into two main categories: tensile and shearing. The

*Correspondence to: Corresponding author. MOE Key laboratory of Deep Earth Science and Engineering, College of Architecture and Environment, Sichuan University, No. 24 South Section 1, Yihuan Road, Chengdu, 610065, P.R. China, Email: geqi@ @scu.edu.cn

\#These authors contributed equally to this work. 
tensile bolted connectors, arranged distributely along the panel-to-panel joint, are mainly materialized by sliding anchor bolts vertically through the prefabricated holes and then securing with nuts. The anchor bolts are stressed mainly in tension when the panel is subjected to lateral force. In the wall system with tensile bolted connectors, the damage is concentrated in the bolt joint, and mainly characterized by concrete crushing and bolt yielding. Overall failure is determined by the failure of the connectors and not by the deformation of the panel, which is different from that of the cast-in-situ concrete structure [13-17]. This wall system can attain large ductility and strength, but it has significant pinching and reduction in energy dissipation for large lateral displacements, due to the plastic deformation of bolts and the loose of nuts which can lead even to residual joint opening [18-19]. When the contact between the adjacent panels is lost, the horizontal resistance decreases significantly and the horizontal slip at the joint increases, as the shear force is undertaken solely by the dowel action of the bolts [20]. Conversely, the shearing bolted connectors can be materialized using connecting steel plates and bolts. The adjoining panels are fastened by passing the bolts horizontally through the prefabricated holes in the connecting steel plates and panels in sequence and securing with nuts. When the panel is subjected to lateral force, the tensile force in the tensile zone of the panel is mainly transferred by the connecting steel plates, which causes the bolts to shear. The experimental and numerical investigation on a series of bolted connectors and bolt-assembled panels were conducted [21-26], and the results concluded that the bolt-assembled precast concrete structure had good integrity and seismic performance including load bearing capacity, energy dissipation ability and ductility. A precast shear wall system utilizing high-strength bolts and H-shaped steel frames was proposed [27], in which the steel frames covered the entire horizontal and vertical joints to connect the adjoining panels. Subsequent experimental and analytical studies [28-32] showed that the integrated bolted connectors were capable of providing sufficient strength to effectively join the adjacent panels together. This wall system exhibited satisfactory seismic performance matching with the cast-in-situ concrete structure [33].

According to the comparison of the connector performances between the tensile and shear bolted connectors in the above literatures, the shear bolted connector has better integrity and seismic performance. The new shear bolted connection method proposed by Chen et al [21] has advantages of high degree of industrialization, rapid construction and high economic benefits, and it is suitable for the low-rise residential building in the vast rural areas of China. Therefore, this paper adopted the bolt connection method [21] to propose a new type of precast concrete sandwich wall panel structure (PCSWPS) with high strength bolts and connecting steel plates for the low-rise residential buildings in villages and towns. This building system uses distributed bolted connectors to adjoin precast panels, slabs and connecting columns. The bolt joints are easy to install and disassembly so that they are replaceable, which make the structure demountable and reassembled. This new system possess advantages of high degree of industrialization, rapid construction and high economic benefits, simple and clear force transferring paths, and good thermal insulation performance, and is suitable for low-rise residential building in the vast rural areas of China. The bolt joints should be properly strengthened, and the joints can be damaged, however, the joints have no earlier damage than the panels. The failure of PCSWPS is expected to be similar with that of a cast-in-situ concrete structure. Shake table testing of a fullscale two-story structure model was conducted to investigate the seismic performance of the proposed structural system. The damage pattern, the dynamic characteristics and the dynamic response were studied to verify the proposed structural system.

\section{Proposal for a novel bolt - assembled PCSWPS}

A novel type of bolt - assembled PCSWPS system was proposed for rural low-rise residential buildings in earthquake zones. The PCSWPS system is composed of PCSW panels bearing horizontal and vertical forces, precast L, $\mathrm{T}$ and cross-shaped connecting corner columns in order to strengthen the connection, precast floor slabs (roof slabs), and steel-bolted connections with high strength bolts and steel plates, as shown in Figs. 1, 2 and 3.

The walls are load-bearing precast concrete sandwich thermal insulation composite wall panels consisting of an inner wall panel, an intermediate sandwich insulation material and an external wall panel, with a total thickness of 200 $\mathrm{mm}$. The inner and external wall panels are reinforced concrete wall panels with a thickness of $70 \mathrm{~mm}$. The intermediate sandwich insulation is an extruded polystyrene (XPS) thermal insulation panel with a thickness of $60 \mathrm{~mm}$. The wall panels are connected through steel plates and high strength steel bolts, in which a panel-to-panel joint (vertical joint) and a panel-floor slab-panel joint (horizontal joint) are as shown in Fig. 1. Along the perimeter of the wall panel, solid inner beams and columns are arranged in order to connect with other components. Bolt holes are reserved by the embedded PVC pipes. The same bolt holes are reserved in the floor slabs and corner columns. During construction, after the components are placed in fixed positions, the connecting steel plates are then placed, and bolts pass through steel plates and wall panels to make connections. The connecting steel plates between the wall panel and the corner column are rectangular, whereas on the floor slab joints, connecting steel plates are L-shaped. To hide the connecting plates to keep the wall level, grooves with $25 \mathrm{~mm}$-thickness are made in the joint areas. The precast floors are recessed inward at the four corners to reserve the positions of the corner columns and ensure the precast corners connection up and down (as shown in Fig.1). Precast corner columns are to connect components in perpendicular directions and improve overall integrity. According to their locations, the sections can be L-shaped, T-shaped or cross-shaped columns, as shown in Fig. 1. Adjacent upper and lower precast columns are connected to each other by semi-grouting sleeves. 


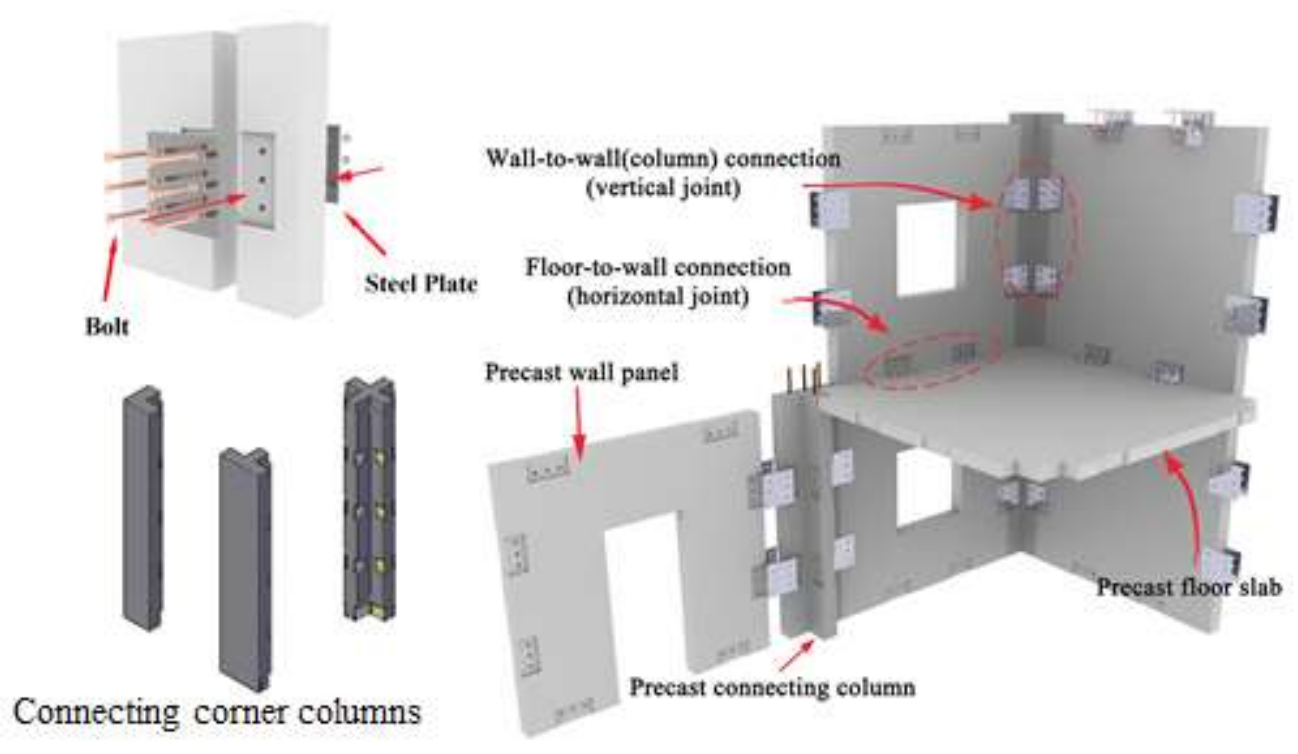

Fig. 1 Schematic diagram of bolt joint connection in the bolt - assembled PCSWPS system

\section{Test model design}

\subsection{Overview of the Prototype and model structures}

The prototype structure represented a two-story rural building in Chengdu, China. The length and width of the building were $11 \mathrm{~m}$ and $9.9 \mathrm{~m}$, respectively, with a height of $2.8 \mathrm{~m}$ and a total area of $217.8 \mathrm{~m}^{2}$. The layout of the building is shown in Fig. 2 (a). It was assigned to design seismic intensity of 7 degree and site class II. According to the above prototype building and considering the bearing capacity of the shake table. the prototype structure in the blue dashed line in Fig. 2 (a) was selected. The test building was $6.2 \times 4.1 \mathrm{~m}$ in plan and had a total height of $6.4 \mathrm{~m}$ with each floor-to-floor height equal to $2.8 \mathrm{~m}$ for the first and second floor levels. The total weight was 96.4 tons, of which the base weight was 24.2 tons. According to GB50009 [34], the floor mass block of 4.8 tons was added to represent the design live load. All the precast components of the test model were manufactured in a precast component factory. It included 14 wall panels, 4 floor panels, 8 L-shaped columns, 4 T-shaped columns, and 1 foundation beam. 1284 high strength bolts, 237 connecting steel plates, and 104 semi-grouting sleeves were used to complete the assembly of 31 precast components. The other design details are listed as follows. The concrete strength grade was C40. All steel bars were HRB400.The connecting steel plate was Q235B. The model structure after installation is shown in Fig. 2 (b).

After the first seismic excitation on the full-scale two-story test building (termed as "Model-1") was completed, no visible cracks were observed on the model structure, and the fundamental frequencies remained almost unchanged undergoing all loading cases. The test building showed strong integrity. In order to understand the seismic damage to the fully bolt-assembly wall system, a weakened model was need to sequentially loading. The longitudinal rebar of the columns connecting with the foundation in the first floor was cut, and some edge bolts in the bolted connectors at the bottoms of the walls in the first floor were removed. The new modified model (termed as "Model-2") structure represented a fully bolt-assembled system, and it was tested using the same loading protocol as the Model-1. The results in the paper mainly referred to the Model-2. 


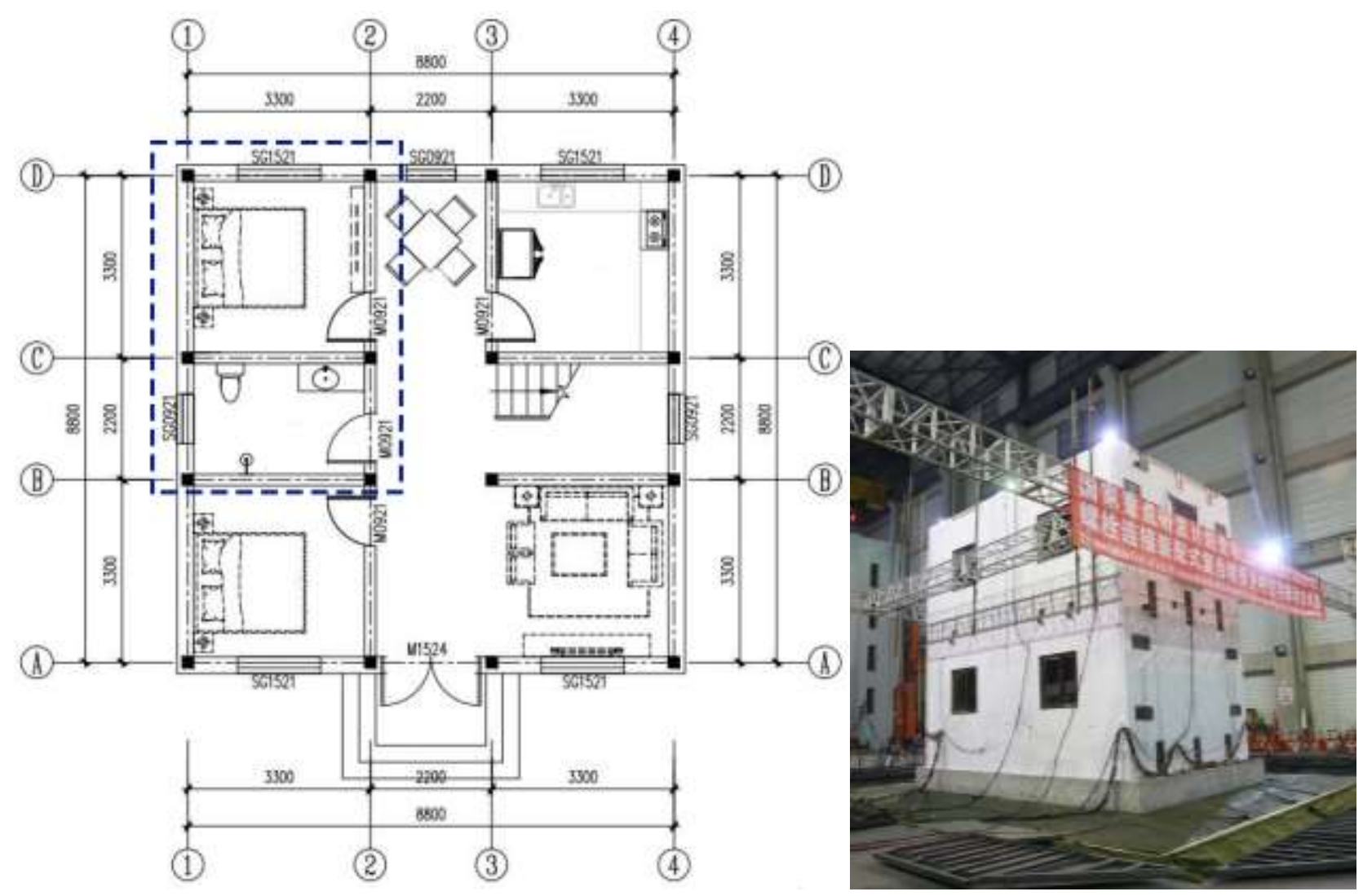

(a) Plan view of the prototype structure

(b) The model structure

Fig. 2 Prototype structure and the model structure

\subsection{Details of the model structure}

\subsubsection{Design method}

The bolt-assembled PCSWPS system proposed in this paper is expected to achieve the same seismic performance of the cast-in-place structure, so the precast concrete composite wall panel was designed according to the cast-in-place structure. The minimum reinforcement rate of the wall can meet the seismic performance requirement. The connection design philosophy in the horizontal joints can be summarized that the bolt-assembled precast panel was designed to be equivalent to a cast-in-situ RC wall with the same strength and similar failure mode. The bolt joints were designed according to the shear capacity and bending capacity that the designed precast composite wall panels could bear, so as to ensure that the wall panels have the same seismic capacity as the cast-in-place walls. Design parameters of bolt connection joints were then obtained through formula calculation according to the calculation formula of the bending bearing capacity and the tensile bearing capacity of the bolt-assembled joint proposed by Chen et al. [21] and Section 12.4.1 in the Standard for design of steel structures [35], such as diameter, number, hole spacing and edge spacing of the bolts, and the dimentions of connecting steel plates. The precast components of the test model were designed according to the Code for design of concrete structures [36], Technical specification for precast concrete structures [37], and Technical specification for multi-story precast concrete structures [38]. The connections should be properly strengthened by using high-strength bolts and widening the distance from the prefabricated holes to the horizontal joint to enable failure of the bolted connectors to occur no earlier than that of the panels.

\subsubsection{Details of components}

\subsubsection{Precast concrete wall panels}

The walls, shown in Fig. 3 (a), are named W-1 through W-7. Walls W-1, W-2, and W-3 without openings were parallel to the Y direction, and Walls W-4 through W-7 with window and door openings were parallel to the $\mathrm{X}$ direction. The inner and external wall panels included distributing bars in the horizontal and vertical directions of $8 \mathrm{~mm}$ in diameter and hook-type stirrups were used to connect each other. Detailed drawings for the wall panels are shown in Figs. 3 (b) to (d). The rebar spacings were $200 \mathrm{~mm}$ and $300 \mathrm{~mm}$, respectively, and the reinforcement ratios were $0.36 \%$ and $0.24 \%$, respectively. Invisible constructional columns of width $270 \mathrm{~mm}$ were arranged on both sides of the wall panel. The invisible beams in the top and bottom of the wall panels were of height $350 \mathrm{~mm}$. The longitudinal reinforcement diameters of constructional columns and beams were $12 \mathrm{~mm}$ and $8 \mathrm{~mm}$, respectively, and the stirrup 
diameter was $6 \mathrm{~mm}$ with spacings $200 \mathrm{~mm}$ and $100 \mathrm{~mm}$, respectively. The concrete cover thickness of the wall panel was $35 \mathrm{~mm}$.

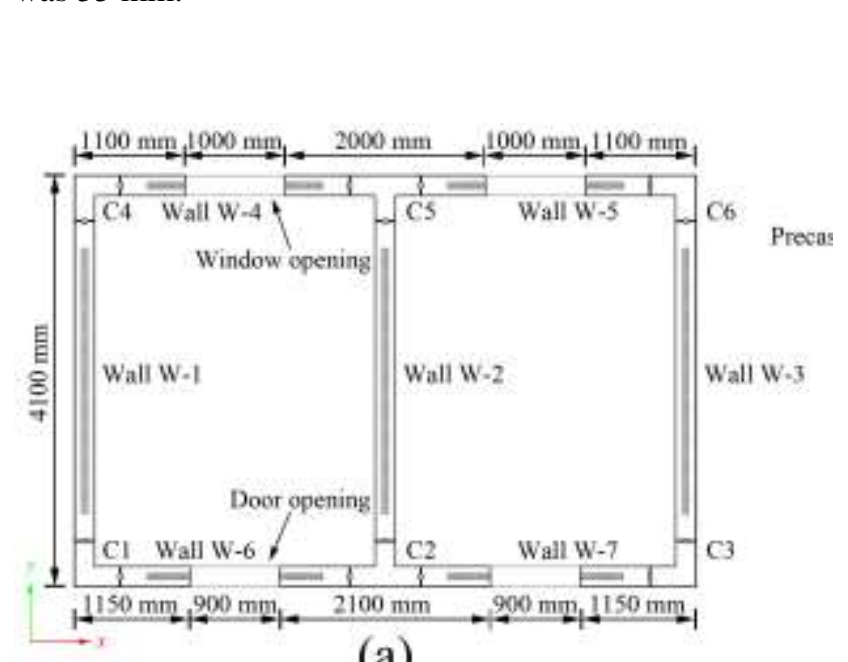

(a)

(a) Plan view of the model structure
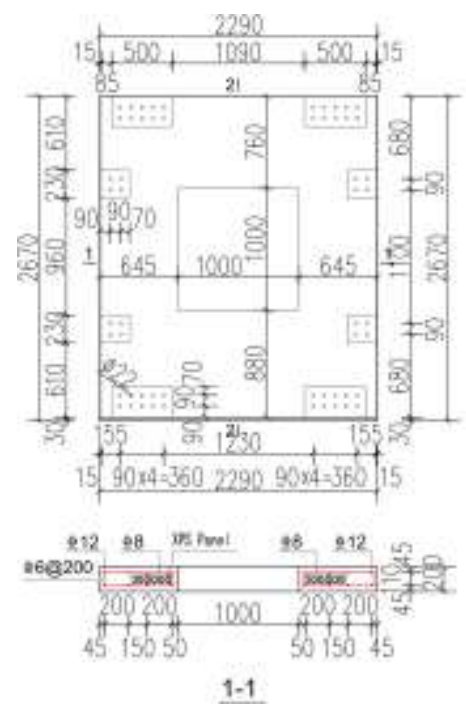

(c) Wall panel with window opening

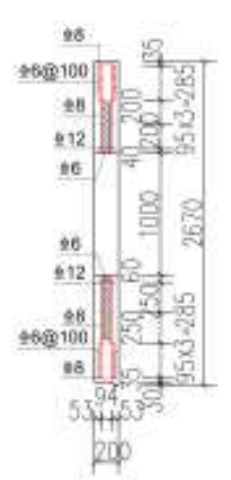

$2-2$
Precas
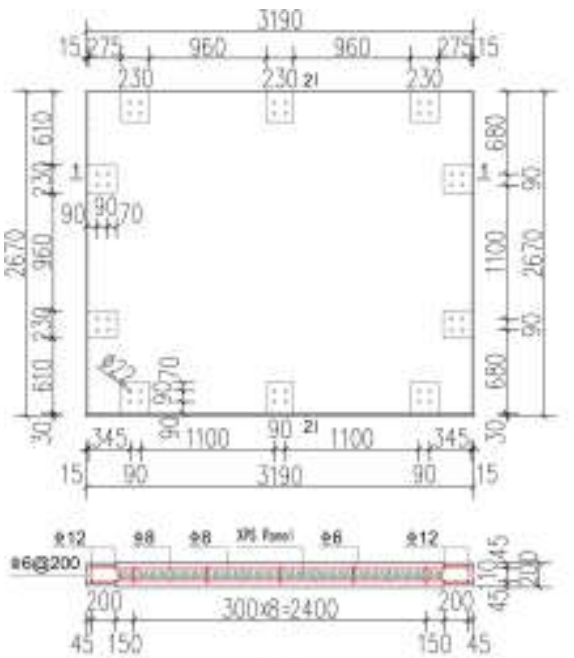

$1-1$

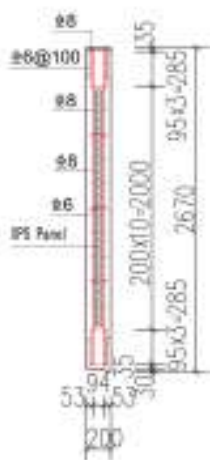

2-2 (b) Wall panel without opening
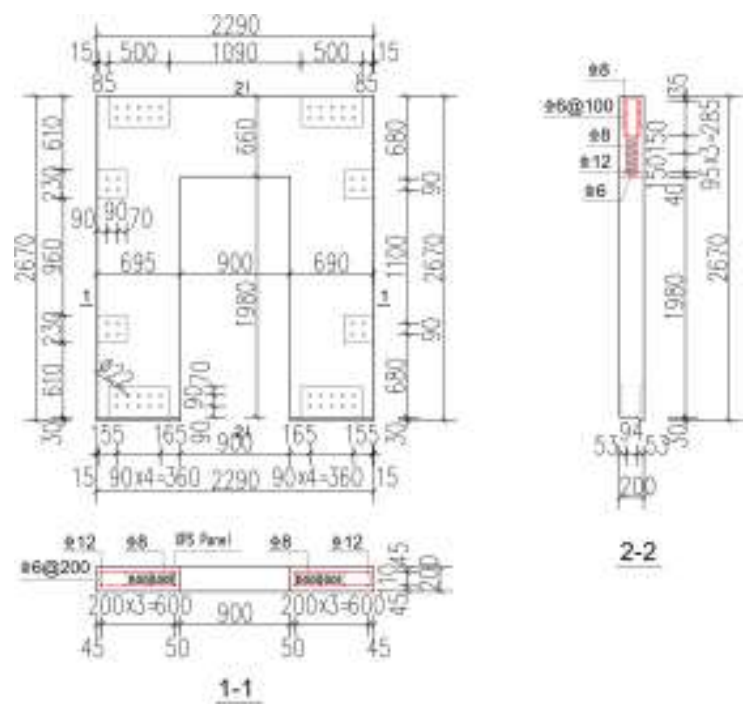

2-2

Fig. 3 Wall panel layout and reinforcement details

\subsubsection{Precast floor slabs and columns}

Each floor diaphragm consisted of two precast reinforced concrete (RC) slabs supported on the walls. The thickness of the precast floor panel was $120 \mathrm{~mm}$, and the thickness of the reinforcement cover was $25 \mathrm{~mm}$. Bidirectional double reinforcements were adopted. The diameter of the distributed reinforcement was $8 \mathrm{~mm}$ and the spacing was $200 \mathrm{~mm}$. Stirrups were added around the floor panel, also like the invisible beam, to ensure reliable connections between the floor panel and the wall panel. The diameter of the stirrups was $6 \mathrm{~mm}$ and the spacing of the stirrups was $200 \mathrm{~mm}$.The dimensions of the first floor and roof were different due to the different horizontal seams on different floors. The plan dimensions and details of the floor are shown in Fig. 4.

The connecting columns, having two types with T- and L-shaped cross-sections, are named C-1 through C-6, as shown in Fig. 3 (a). The height of the precast corner columns was $2780 \mathrm{~mm}$, and the thickness of the reinforcement cover was $35 \mathrm{~mm}$. The diameters of the longitudinal reinforcement and stirrup were $14 \mathrm{~mm}$ and $6 \mathrm{~mm}$, respectively. The stirrup spacing in the encrypted and unencrypted areas were $100 \mathrm{~mm}$ and $200 \mathrm{~mm}$, respectively. The bottom of each longitudinal reinforcement in the column was connected with a semi-grouting sleeve. The details are shown in Fig.5. 


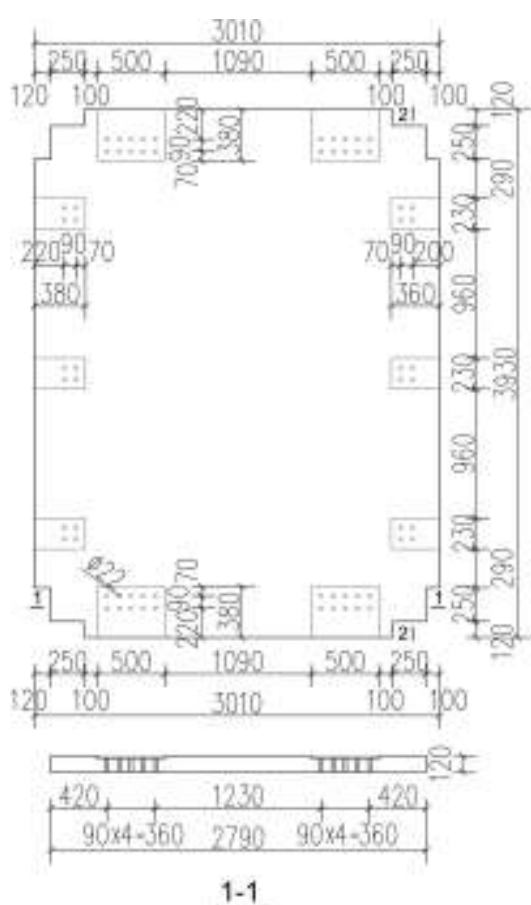

(a) The first floor slab

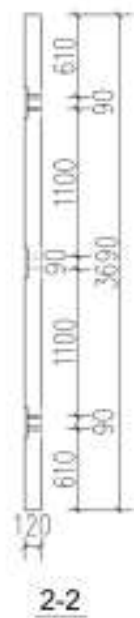

Fig. 4 Dimensions of floor slab and roof

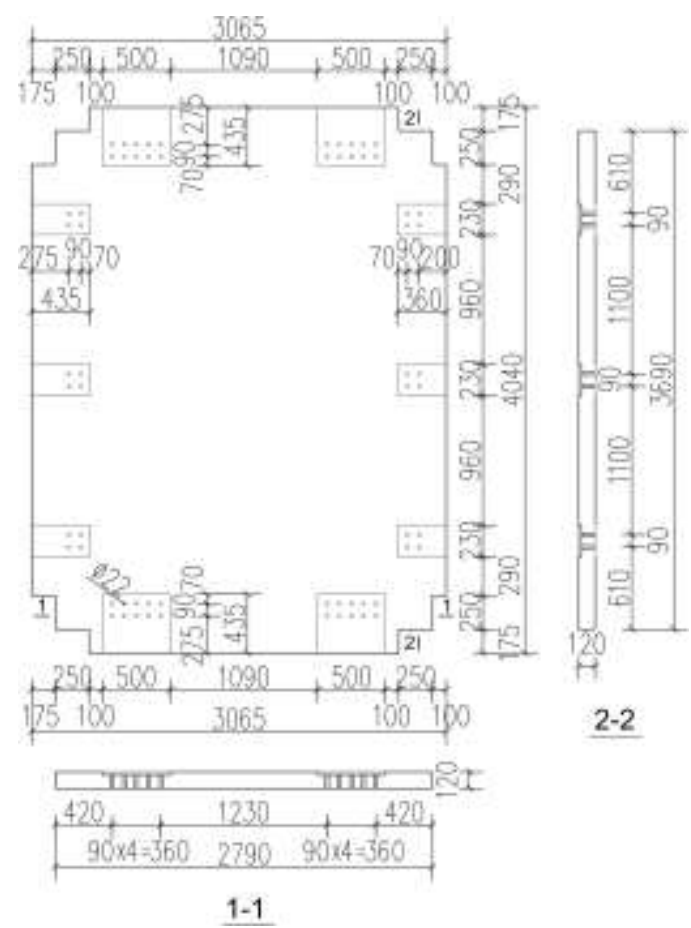

(b) The roof slab
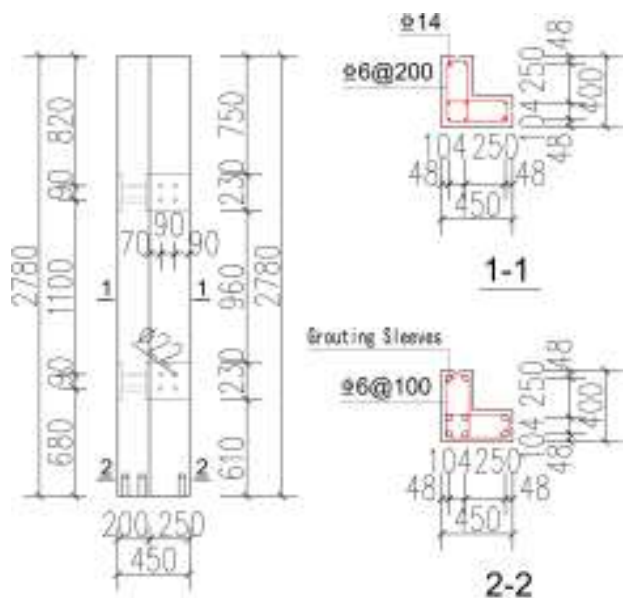

$1-1$

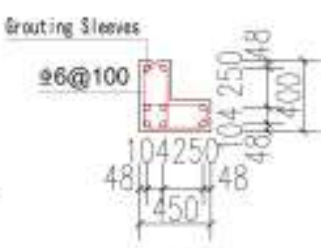

$2-2$
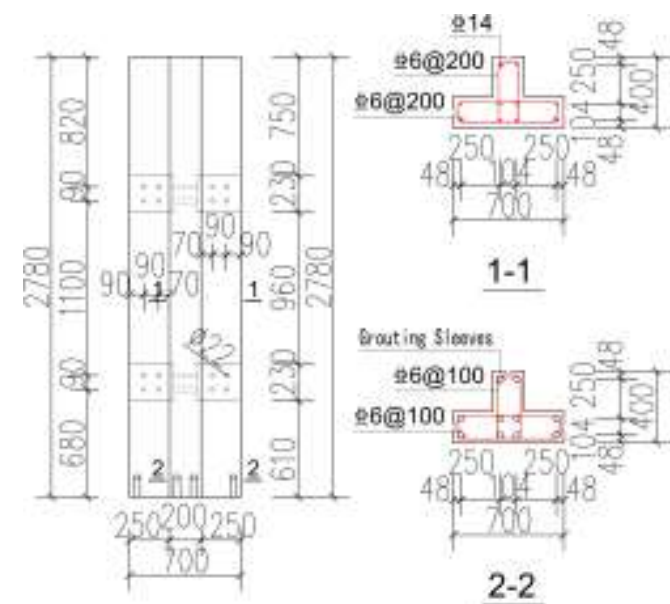

$1-1$

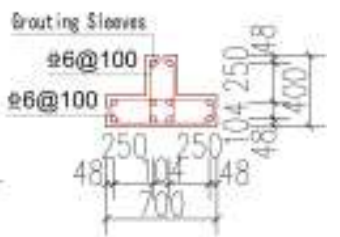

2-2

(a) Dimensions and reinforcement of L-shaped column (b) Dimensions and reinforcement of T-shaped column

Fig. 5 Dimensions and reinforcement of L-shaped and T-shaped columns

3.2.2.3 Bolt-connected joints

According to the previous design method, the connection design parameters were obtained by using the strength calculation formulas proposed by Chen et al. [21] for bolted connector and bolt-assembled panel. As a result, the diameter of high-strength bolts was $16 \mathrm{~mm}$, the thickness of connecting steel plates was $8 \mathrm{~mm}$ and the distance from the prefabricated holes to the horizontal joint was $90 \mathrm{~mm}$. The dimensions of connecting steel plates with four types are sketched in Fig. 6 and Table 1. The same connection design parameters were applied in the walls with openings (i.e. W4 through W-7) except that more high-strength bolts and larger connecting steel plates were adopted to cover the entire horizontal joints and form integrated bolted connectors in every piers. Based on previous studies, two distributed bolted connectors were arranged evenly along each vertical joint to make the walls in two directions work together. In short, 107 bolted connectors including 1294 high strength bolts and 237 connecting steel plates were used in the horizontal and vertical joints. 


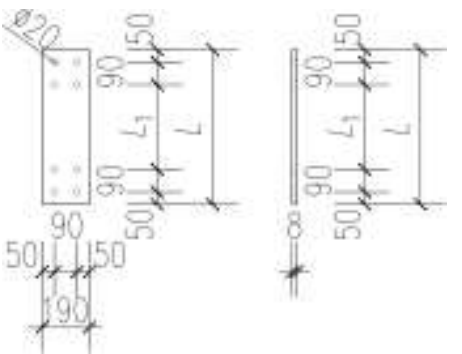

(a) Type I
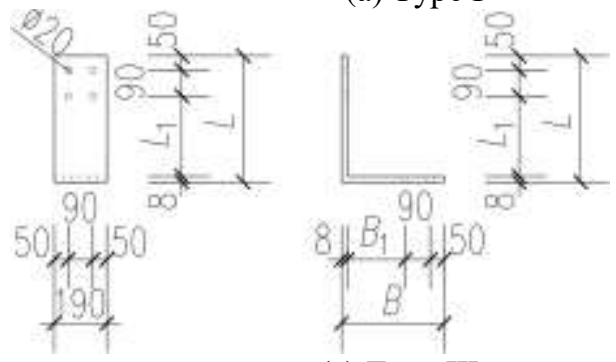

(c) Type III

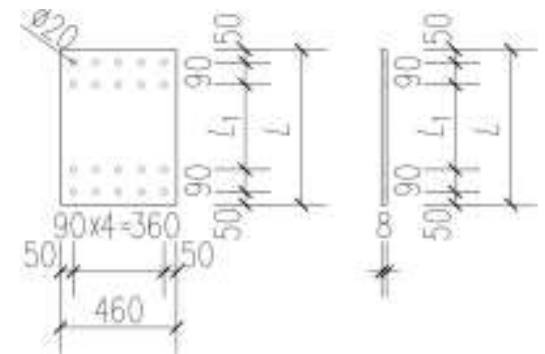

(b) Type II
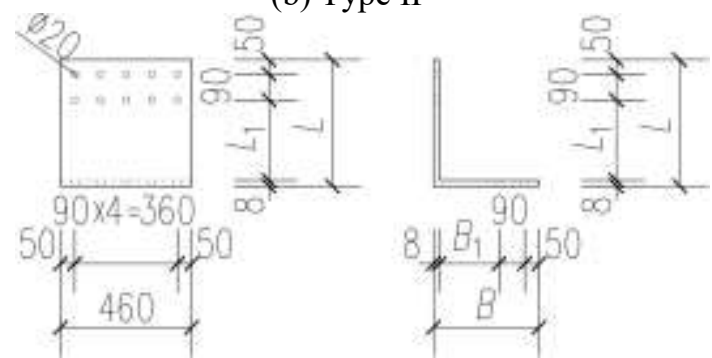

(d) Type IV

Fig. 6 Connection steel plates

Table 1 Dimension and weight of steel plates

\begin{tabular}{cccccccc}
\hline Type & ID & $L / \mathrm{mm}$ & $L_{1} / \mathrm{mm}$ & $\boldsymbol{B} / \mathrm{mm}$ & $B_{1} / \mathrm{mm}$ & Number & Weight $/ \mathrm{kg}$ \\
\hline \multirow{5}{*}{ I } & GB1 & 465 & 185 & - & - & 112 & 617.12 \\
& GB2 & 480 & 200 & - & - & 18 & 102.42 \\
& GB3 & 620 & 340 & - & - & 6 & 44.10 \\
& GB4 & 690 & 410 & - & - & 3 & 24.54 \\
\hline \multirow{2}{*}{ II } & GB5 & 480 & 200 & - & - & 16 & 220.48 \\
& GB6 & 620 & 340 & - & - & 8 & 142.40 \\
\hline \multirow{3}{*}{ III } & GB7 & 250 & 102 & 270 & 122 & 24 & 145.68 \\
& GB8 & 270 & 122 & 270 & 122 & 12 & 75.72 \\
& GB9 & 428 & 280 & 358 & 210 & 6 & 55.32 \\
\hline \multirow{3}{*}{ IV } & GB10 & 250 & 102 & 250 & 102 & 16 & 235.20 \\
& GB11 & 270 & 122 & 270 & 122 & 8 & 122.16 \\
& GB12 & 428 & 280 & 358 & 210 & 8 & 178.64 \\
\hline
\end{tabular}

\subsubsection{Material properties}

The cube compressive strength, axial compressive strength, axial tensile strength and elastic modulus of the concrete were $54.56 \mathrm{MPa}, 41.47 \mathrm{MPa}, 3.56 \mathrm{MPa}$, and $3.52 \times 104 \mathrm{MPa}$, respectively. The mechanical properties of steel bars and steel plates are shown in Table 2 . The flexural strength and compressive strength of grouting material were 10.49 MPa and 90.55 MPa, respectively. The yield strength and ultimate strength of the semi-grouting sleeve were 453 $\mathrm{MPa}$ and $635 \mathrm{MPa}$, respectively.

Table 2 Mechanical properties of reinforcements and steel plates

\begin{tabular}{ccccc}
\hline Type & Diameters/mm & Yield strength/ MPa & $\begin{array}{c}\text { Ultimate tensile } \\
\text { strength/ MPa }\end{array}$ & Elongation/ \% \\
\hline \multirow{3}{*}{ Reinforcements } & 6 & 434 & 617 & 32.0 \\
& 8 & 442 & 636 & 27.5 \\
Steel plate & 12 & 450 & 641 & 34.0 \\
& 14 & 452 & 629 & 31.0 \\
& 22 & 468 & 639 & 18.5 \\
\end{tabular}

\section{Experimental programme}

4.1 Earthquake inputs and loading sequence

The El Centro earthquake wave, Kobe earthquake wave and an artificial earthquake wave were selected as the excitation inputs. The scaling of these ground motions was done according to the Chinese code GB50011 [39] for a 
location in Chengdu, China. Intensities were selected based on levels corresponding to the design basis earthquake and maximum considered earthquake with peak ground acceleration (PGA) equal to $0.10 \mathrm{~g}$ and $0.22 \mathrm{~g}$, respectively. In order to evaluate the seismic performance of the model structure at higher seismic intensity levels, the intensities corresponding to maximum considered earthquake of the seismic design intensity 7.5, 8, 8.5, and 9 were applied, the PGA of which were equal to $0.31 \mathrm{~g}, 0.40 \mathrm{~g}, 0.51 \mathrm{~g}$, and $0.62 \mathrm{~g}$, respectively.

The loading process included six stages: $0.10 \mathrm{~g}$ (7-degree fortification earthquake), $0.22 \mathrm{~g}$ (7-degree rare earthquake), $0.31 \mathrm{~g}$ (7.5-degree rare earthquake), $0.40 \mathrm{~g}$ (8-degree rare earthquake), $0.51 \mathrm{~g}$ (8.5-degree rare earthquake), and $0.62 \mathrm{~g}$ (9-degree rare earthquake). The model was excited by white noise before and after the earthquake inputs at different levels to obtain the dynamic characteristics. At each stage of the motions with different intensity level, biaxial El Centro ground motion was applied, followed by the Kobe and the artificial ground motions. Finally, the model was loaded at $0.80 \mathrm{~g}$ peak acceleration to evaluate the seismic performance of the structure under the excitation of a rare earthquake exceeding 9 degrees. he loading sequence is shown in Table 3.

Table 3 Loading sequence

\begin{tabular}{|c|c|c|c|c|c|c|}
\hline \multirow[b]{2}{*}{ Model } & \multirow[b]{2}{*}{ Number } & \multirow[b]{2}{*}{ Case ID } & \multirow[b]{2}{*}{ Fortification intensity } & \multirow{2}{*}{$\begin{array}{c}\text { Main } \\
\text { vibration } \\
\text { direction }\end{array}$} & \multicolumn{2}{|c|}{ Peak acceleration/g } \\
\hline & & & & & $X$ & $Y$ \\
\hline \multirow{19}{*}{ Model-1 } & 1 & WN1 & White noise & & 0.03 & 0.03 \\
\hline & $2 / 4 / 6$ & EXY1/ KXY1/AX1 & \multirow{2}{*}{$\begin{array}{l}7 \text { degrees of } \\
\text { fortification } \\
\text { earthquake) }\end{array}$} & \multirow{2}{*}{$\begin{array}{l}X \\
Y\end{array}$} & 0.10 & $0.08 / 0.07 /-$ \\
\hline & $3 / 5 / 7$ & EYX1/ KYX1/AY1 & & & $0.08 / 0.07 /-$ & 0.10 \\
\hline & 8 & WN2 & White noise & & 0.03 & 0.03 \\
\hline & $9 / 11 / 13$ & EXY2/ KXY2/AX2 & 7 degrees of rare & $X$ & 0.22 & $0.17 / 0.16 /-$ \\
\hline & $10 / 12 / 14$ & EYX2/ KYX2/AY2 & earthquake & $Y$ & $0.17 / 0.16 /-$ & 0.22 \\
\hline & 15 & WN3 & White noise & & 0.03 & 0.03 \\
\hline & $16 / 18 / 20$ & EXY3/ KXY3/AX3 & 7.5 degrees of rare & $X$ & 0.31 & $0.23 / 0.22 /-$ \\
\hline & $17 / 19 / 21$ & EYX3/ KYX3/AY3 & earthquake & $Y$ & $0.23 / 0.22 /-$ & 0.22 \\
\hline & 22 & WN4 & White noise & & 0.03 & 0.03 \\
\hline & $23 / 25 / 27$ & EXY4/ KXY4/AX4 & 8 degrees of rare & $X$ & 0.40 & $0.30 / 0.28 /-$ \\
\hline & $24 / 26 / 28$ & EYX4/ KYX4/AY4 & earthquake & $Y$ & $0.30 / 0.28 /-$ & 0.40 \\
\hline & 29 & WN5 & White noise & & 0.03 & 0.03 \\
\hline & $30 / 32 / 34$ & EXY5/ KXY5/AX5 & 8.5 degrees of rare & $X$ & 0.51 & $0.38 / 0.36 /-$ \\
\hline & $31 / 33 / 35$ & EYX5/ KYX5/AY5 & earthquake & $Y$ & $0.38 / 0.36 /-$ & 0.51 \\
\hline & 36 & WN6 & White noise & & 0.03 & 0.03 \\
\hline & $37 / 39 / 41$ & EXY6/ KXY6/AX6 & 9 degrees of rare & $X$ & 0.62 & $0.47 / 0.44 /-$ \\
\hline & $38 / 40 / 42$ & EYX6/ KYX6/AY6 & earthquake & $Y$ & $0.47 / 0.44 /-$ & 0.62 \\
\hline & 43 & WN7 & White noise & & 0.03 & 0.03 \\
\hline \multirow{21}{*}{ Model-2 } & 44 & WN8 & White noise & \multirow{3}{*}{$\begin{array}{l}X \\
Y\end{array}$} & 0.03 & 0.03 \\
\hline & $45 / 46 / 47$ & EXY8/ KXY8/AX8 & \multirow{2}{*}{$\begin{array}{l}7 \text { degrees of } \\
\text { fortification } \\
\text { earthquake }\end{array}$} & & 0.10 & $0.08 / 0.07 /-$ \\
\hline & 48 & AY8 & & & - & 0.10 \\
\hline & 49 & WN9 & White noise & & 0.03 & 0.03 \\
\hline & $50 / 51 / 52$ & EXY9/ KXY9/AX9 & 7 degrees of rare & $X$ & 0.22 & $0.17 / 0.16 /-$ \\
\hline & 53 & AY9 & earthquake & $Y$ & - & 0.22 \\
\hline & 54 & WN10 & White noise & & 0.03 & 0.03 \\
\hline & $55 / 56 / 57$ & EXY10/ KXY10/AX10 & 7.5 degrees of rare & $X$ & 0.31 & $0.23 / 0.22 /-$ \\
\hline & 58 & AY10 & earthquake & $Y$ & - & 0.22 \\
\hline & 59 & WN11 & White noise & & 0.03 & 0.03 \\
\hline & $60 / 61 / 62$ & EXY11/ KXY11/AX11 & 8 degrees of rare & $X$ & 0.40 & $0.30 / 0.28 /-$ \\
\hline & 63 & AY11 & earthquake & $Y$ & - & 0.40 \\
\hline & 64 & WN12 & White noise & & 0.03 & 0.03 \\
\hline & $65 / 66 / 67$ & EXY12/ KXY12/AX12 & 8.5 degrees of rare & $X$ & 0.51 & $0.38 / 0.36 /-$ \\
\hline & 68 & AY12 & earthquake & $Y$ & - & 0.51 \\
\hline & 69 & WN13 & White noise & & 0.03 & 0.03 \\
\hline & $70 / 71 / 72$ & EXY13/ KXY13/AX13 & 9 degrees of rare & $X$ & 0.62 & $0.47 / 0.44 /-$ \\
\hline & 73 & AY13 & earthquake & $Y$ & - & 0.62 \\
\hline & 74 & WN14 & White noise & & 0.03 & 0.03 \\
\hline & 75 & EXY14 & $0.80 \mathrm{~g}$ & $X$ & 0.80 & 0.60 \\
\hline & 76 & WN15 & White noise & & 0.03 & 0.03 \\
\hline
\end{tabular}


Note: WN represents white noise; EXY and EYX represent the cases of $\mathrm{X}$ and $\mathrm{Y}$ main vibration directions under the excitation of the bidirectional XY input of El Centro wave, respectively, KXY and KYX are the cases of X and Y main vibration directions under the excitation of the bidirectional XY input of Kobe wave, respectively. AX and AY represent the cases of $\mathrm{X}$ and $\mathrm{Y}$ direction vibrations under the excitation of artificial seismic wave, respectively.

\subsection{Instrumentation and measurements}

Accelerometers and laser displacement sensors were used to measure the acceleration responses and displacement responses in the shake table testing, respectively. Data on acceleration and displacement were collected by the STEX3 data acquisition and processing system of the MTS company. Two accelerometers were arranged in the middle of the shake table to measure the output acceleration of the shake table. Two accelerometers were located at the foundation beam and eight accelerometers were placed on each floor, as shown in Fig. 7. Two laser displacement sensors were placed at two positions between the base and the shaking table to measure the relative slip. Two laser displacement sensors at the upper part of the foundation beam and five displacement sensors on each floor were located to measure the displacements in two directions. The test instrumentation included a total of 20 accelerometers and 14 displacement sensors. The labels of acceleration measuring points and displacement measuring points were in two parts. The first part was measuring point type and position. A and DT represent acceleration measuring and displacement measuring, respectively. $0,1,2$ represent the basement, the first floor and the roof, respectively. The second part is the ordinal number of the sensor. In the ordinal number of the acceleration measuring point, the odd and even numbers are the $\mathrm{X}$ direction and $\mathrm{Y}$ direction acceleration measuring points, respectively. The specific arrangements of the acceleration and displacement measurement points are shown in Fig. 7.
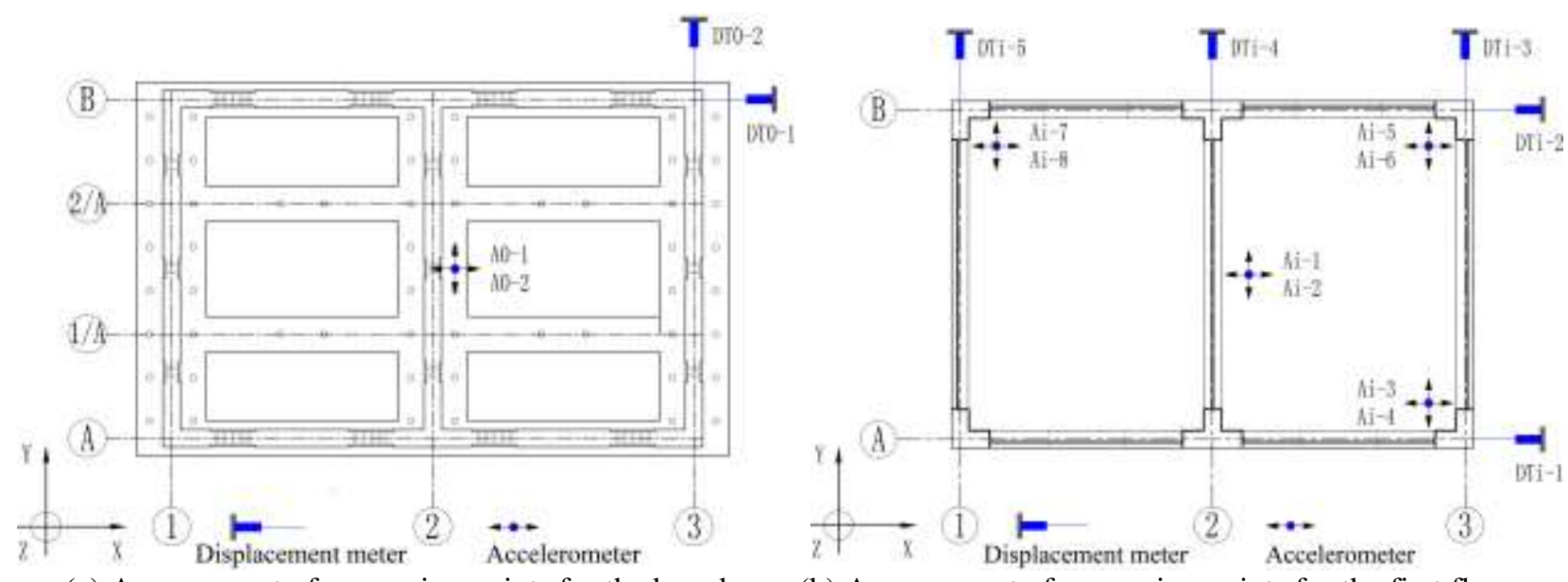

(a) Arrangement of measuring points for the base beam (b) Arrangement of measuring points for the first floor

Fig. 7 Arrangement of measuring points

\section{Experimental results and analysis}

\subsection{Test phenomena and damage patterns}

Damage observation, cracking initiation and propagation were recorded after each loading to analyze the damage process throughout the shake table testing with gradually increasing earthquake inputs. Model-1 only weakly vibrated with no visible cracks after the excitation of $0.10 \mathrm{~g}$ peak acceleration earthquake inputs (Case 7), and the structure did not indicate any change. After the excitations of 7-degree rare earthquake inputs (Case 14), horizontal cracks appeared in the grouting layers at the bottoms of some L-shaped columns on the first floor, as shown in Fig. 8 (a). In the subsequent loadings, no other cracks appeared until excitation of the 9-degree rare earthquake. After the excitations of the 9-degree rare earthquake inputs (Case 42), vertical cracks occurred in the grouting layers at the bottom of a Lshaped columns at the intersection of axes (3) and A in the first floor, as shown in Fig. 8 (b). The Model-1 was basically in a good state and in the elastic stage, with no structural cracks and no obvious residual displacement. The structural system had large space stiffness and good overall performance. The bolt joints were not weak parts in the proposed novel PCSWPS system, and the structure has the same performance as the cast-in-place structure. 

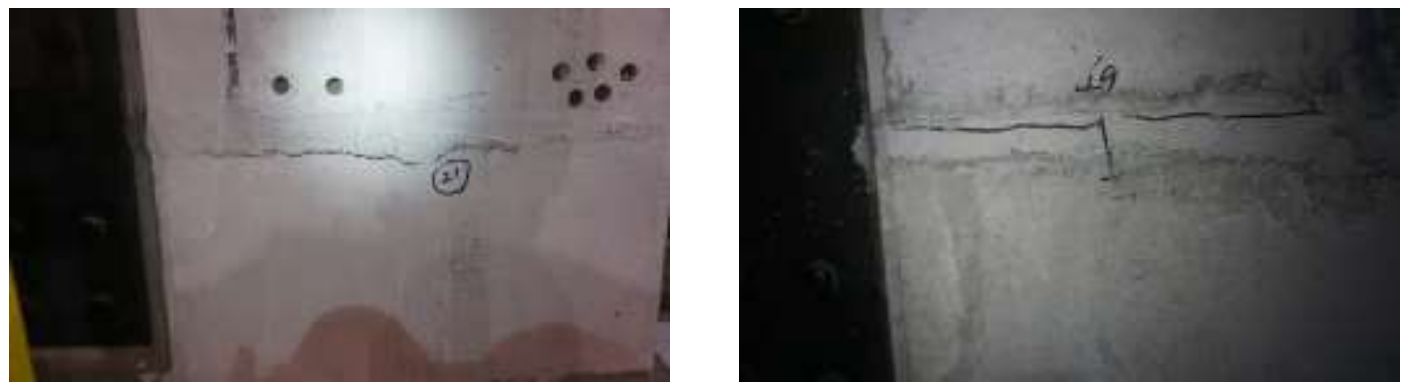

(a) Horizontal crack in the L-shaped column

(b) Vertical crack in the L-shaped column

Fig. 8 Damage in Model--1

The following main phenomena for the Model-2 were identified:

(1) When the peak accelerations were $0.10 \mathrm{~g}$ and $0.22 \mathrm{~g}$, no new visible cracks were observed.

(2) The model was under the excitation of a 7.5-degree rare earthquake with peak acceleration of $0.31 \mathrm{~g}$ that caused the propagation of previous horizontal cracks in the grouting layers at the bottoms of some L-shaped columns on the first floor in the Model-1 and development of new penetrating horizontal cracks in the grouting layers in some columns and between the wall panel and foundation beam; Diagonal cracks could be observed on the top left and right corners of the door opening and the four corners of the window (i.e. W-4 through W-7) on the first floor, as shown in Figs. 9 (a) and (b), and the crack morphology was similar to that of an in-situ cast structure where lateral seismic forces cause large shear deformation at the edges of openings because of high stress concentrations; Some map cracks occurred in the mortar layer covering the bolted connectors on the walls with window openings (i.e. W-4 and W-5) due to deformation of bolted connectors, as shown in Fig. 9 (c).

(3) The model was under the excitation of a 8-degree rare earthquake with peak acceleration of $0.4 \mathrm{~g}$ that caused the new cracks that were propagating from the bolt hole at the horizontal joints of the bottoms of the wall panels (i.e. W-1, W-2, and W-3) on the first floor, as shown in Fig. 9 (d), and these cracks were associated with high contact stresses between the screw and the concrete induced by dowel action of the bolts when the bolted connector was subject to tension; Some new vertical cracks appeared along the vertical joints between the column and wall panel at the bottoms in the first floor due to the strong pressure at the horizontal joints, as shown Fig. 9 (e); Horizontal cracks were found in the grouting layers at the bottoms of all the columns on the second floor; Diagonal cracks in the door and window with openings extended to both sides.

(4) The model was under the excitation of a 8.5-degree rare earthquake with peak acceleration of $0.51 \mathrm{~g}$ that caused horizontal cracks of the filled surface in the joint zone at the top of the wall panels opening in the first floor, as shown in Fig. 9 (f); The diagonal cracks in the door and window openings continued to extend to both sides, and the diagonal cracks at the top corner of the door opening extended to the adjacent vertical joints on both sides of the wall panel.

(5) The model was under the excitation of a 9-degree rare earthquake with peak acceleration of $0.62 \mathrm{~g}$ that caused vertical cracks and the little bits and pieces falling off the concrete at the seams between the wall panels and the columns on the first floor, as shown in Fig. 9 (e); A violent impact between the walls and slabs happened, as evidenced by the formation of new horizontal cracks identified on the panel-to-panel joint of wall W-7 on the first floor level as shown in Fig. 9 (f).

In fact, the test observations above showed that the model structure had good seismic performance even under extreme ground motions. The connecting columns combined the longitudinal and transverse walls to provide a box system characterized by strong resistance and good integrity. The structural damage was mainly concentrated in the wall openings and the bottom of walls and columns, mainly characterized by concrete cracking. During the whole test, at horizontal and vertical joints, there was no relative movement between the steel plate and concrete, the high-strength bolts remain in place, and the holes in the steel plate were not deformed. As expected, in the shake table testing, the damage to the panels occurred before the bolt connectors, which was similar to a cast-in-situ structure where the first is to mobilize the strength of the main structural members, and this demonstrated the effectiveness of the connection design in the model structure. 

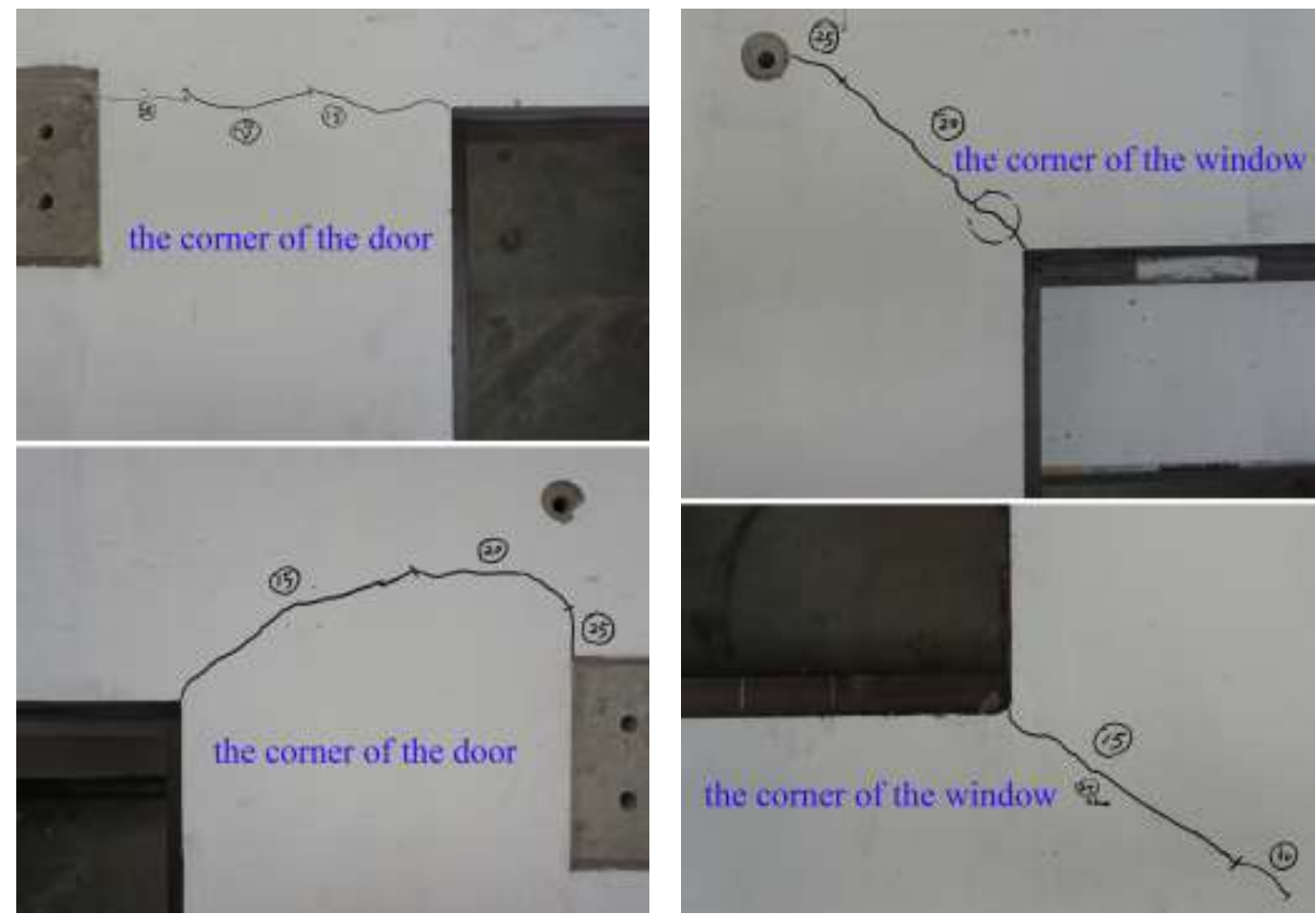

(a) Oblique cracks at the door opening

(b) Oblique cracks at the window opening
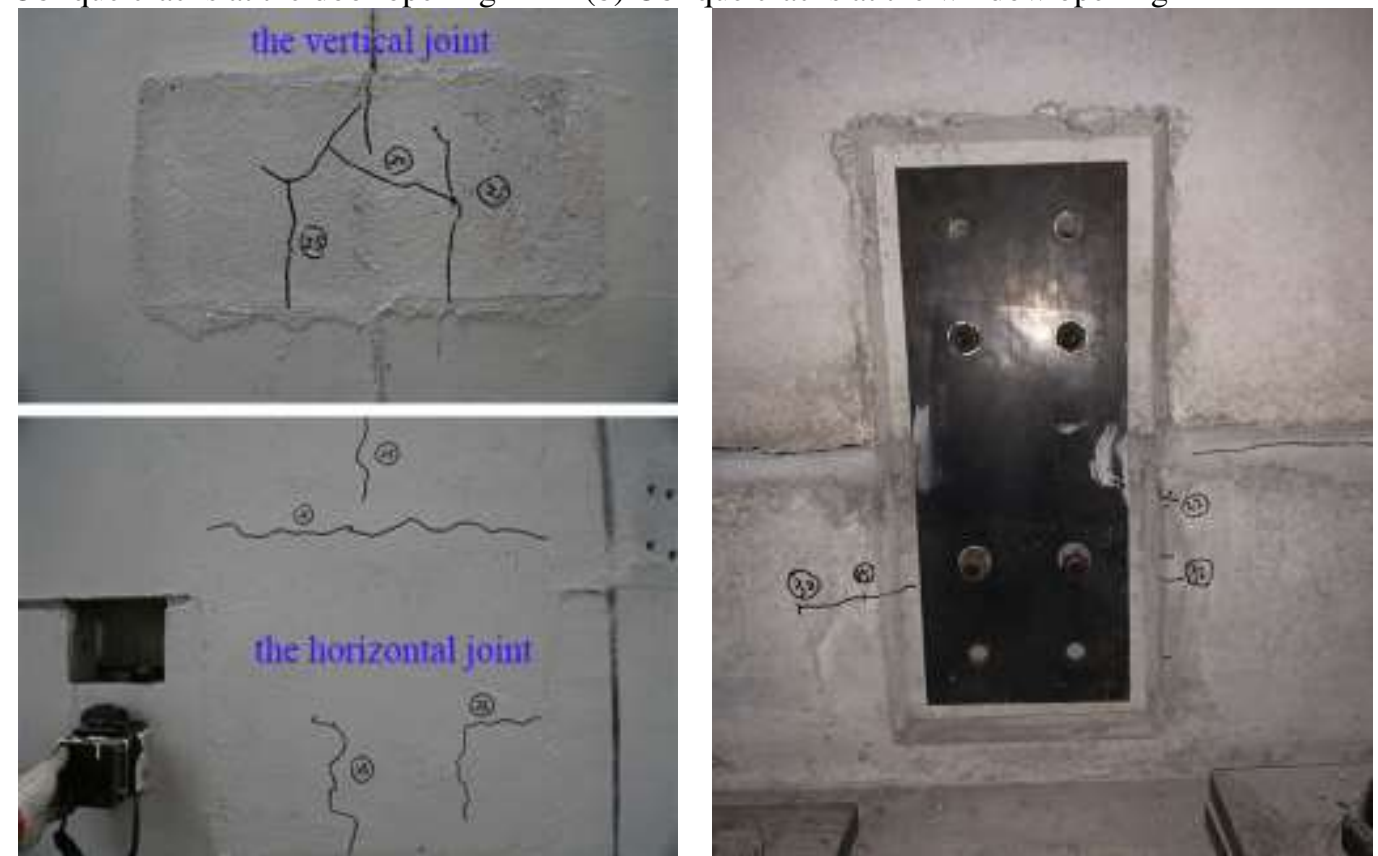

(c) Map cracks on the filled surfaces of joints
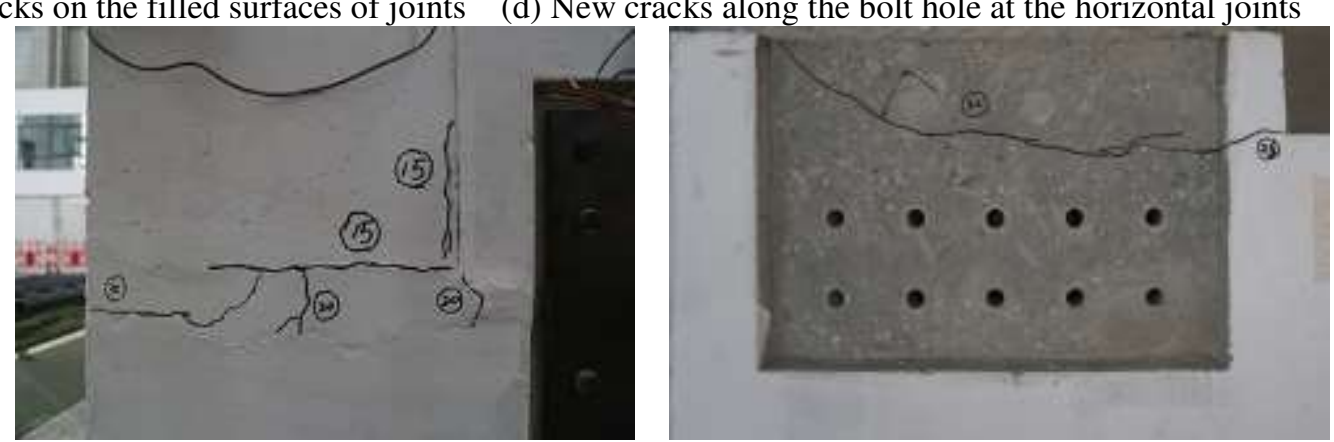

(e) Vertical cracks at column bottom (f) Horizontal cracks in the joint zone at the top of the wall

Fig. 9 Damage in the Model-2 


\subsection{Displacement response and deformation mechanism}

\subsubsection{Displacement profile}

The relative displacement time history of each floor can be obtained by subtracting the displacement time history of the base, and the maximum value of which is the maximum relative displacement of the model. Fig. 10 shows the envelope diagrams of the maximum relative displacement in the Model-1 and the Model-2 under the excitation of EL Centro wave. As a whole, the displacement response of each floor of the two models increased with increasing peak input acceleration. For the Model-1, the maximum relative displacement of each floor was basically an inverted triangle distribution, indicating that the deformation of the model was mainly shear deformation. The maximum relative displacement of the Model-1 was $4.33 \mathrm{~mm}$ with the peak input acceleration of $0.62 \mathrm{~g}$. For the Model-2, under the excitation of $0.10 \mathrm{~g}$, the relative displacement of each floor of the model was basically a straight line, and the structure was in the elastic stage. After the excitation of $0.31 \mathrm{~g}$, diagonal cracks began to appear at the door and window openings on the wall panels, and cracks along the bolt hole walls occurred in the bolt holes at the bottom of the wall panels, which led to the gradual decreasing of the stiffness of the model structure, the continuous increasing of lateral displacement, and increasing relative displacement in the Y direction larger than that in X direction. When $0.62 \mathrm{~g}$ of El Centro was input, the maximum relative displacement value of the model structure was in the $\mathrm{Y}$ direction, and the value was $10.54 \mathrm{~mm}$. Similar to the Model-1, the X direction displacement in the Model-2 was also dominated by shear deformation, whereas, the displacement distribution in the Y direction was different and mainly flexural deformation after the cases of the peak acceleration of $0.31 \mathrm{~g}$. On the whole, the deformation of the structure system presented in this paper was consistent with that of the cast-in-place concrete structure.
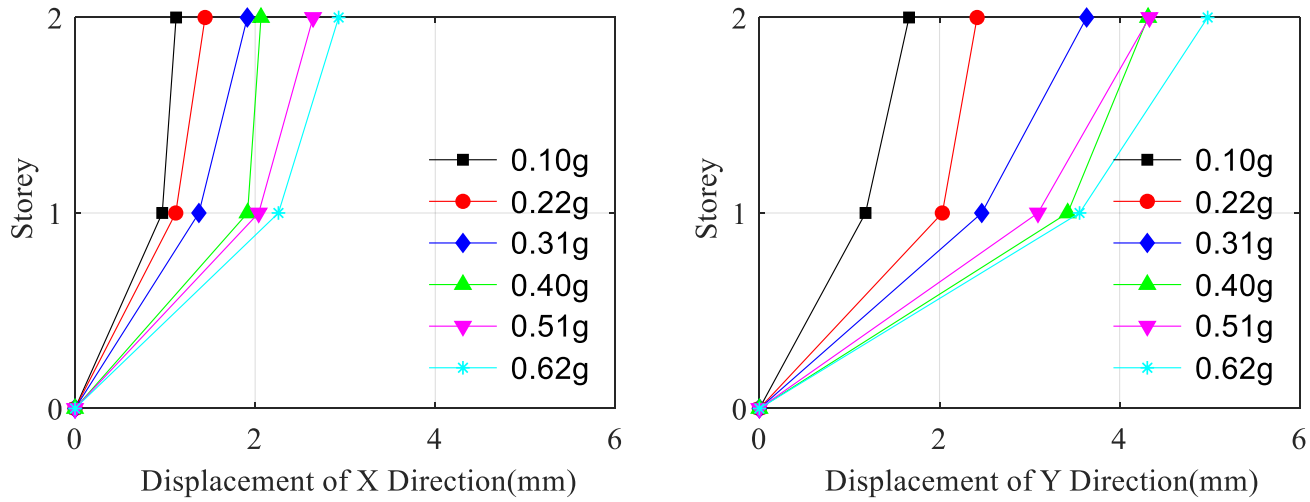

(a) Maximum relative displacement of each floor in the Model-1 under the excitation of EL Centro wave
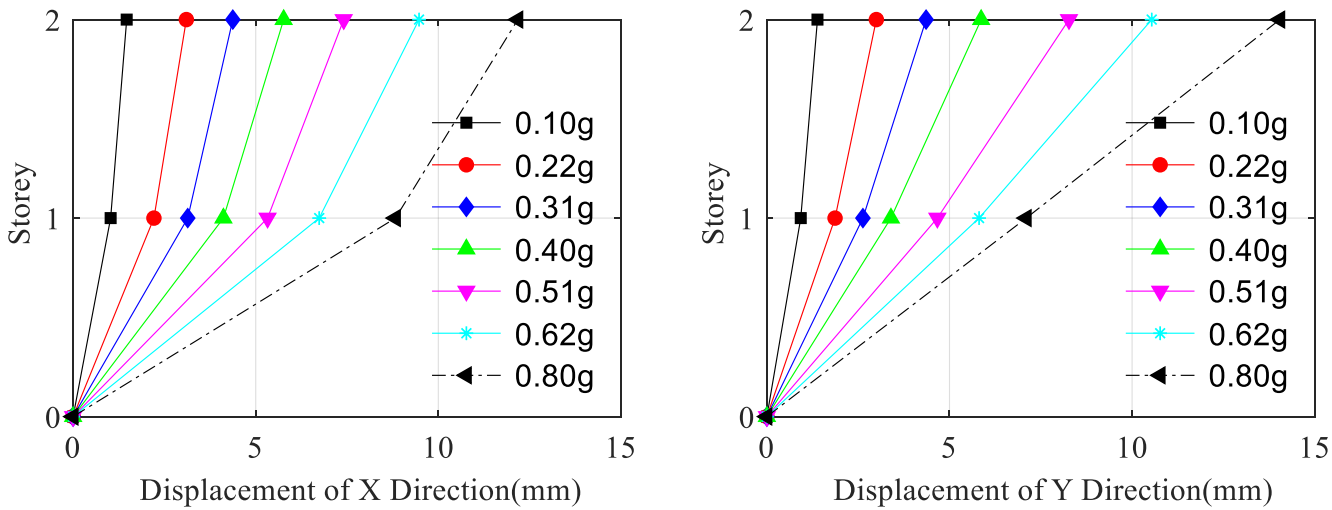

(b) Maximum relative displacement of each floor in the Model-2 under the excitation of EL Centro wave

Fig. 10 Maximum displacement of each floor under the excitation of EL Centro wave

\subsubsection{Inter-story drift angles}

Fig. 11 shows the inter-story drift angles of the Model-2 for all of the tests of El Centro ground motion, and it can be seen that the inter-story drift angles of each story increased significantly according to the ground motion intensity level. As shown in the displacement profile mentioned previously, the drift response on the Model-2 had distinguishing characteristics in $\mathrm{X}$ and $\mathrm{Y}$ directions. In the $\mathrm{X}$ direction, inter-story drift angles in the first story were larger than the second story. The slight soft story behaviour of test building in the first story can be attributed to the deformation mechanism of the longitudinal walls dominated by in-plane shear. This is particularly evident in the inter-story drift angle results after EC-0.31, where it can be seen that the inter-story drift angles in the first story has 1.5 times of those in the second story. However, the inter-story drift angles of the first and second floor levels in the Y direction were almost close to each other before EC-0.22, while after that the inter-story drift angles in the second story were 
significantly much greater, indicating the in-plane bending response of the transverse walls over the height of the structure. In addition, the inter-story drift angles of test building in the $\mathrm{Y}$ direction were slight larger than those in the $\mathrm{X}$ direction at the same motion intensity level even though the PGA was lower than in the X direction, indicating that the model structure had greater deformation capacity in the Y direction.

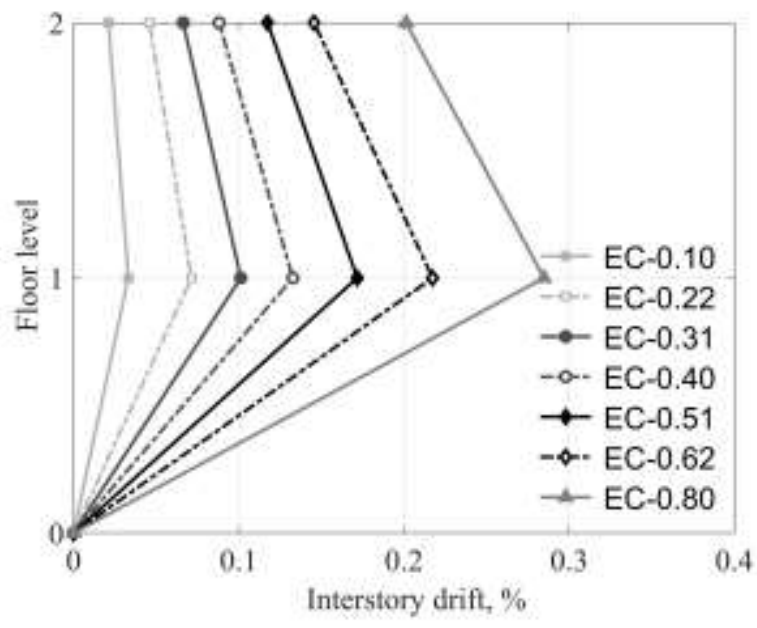

(a)

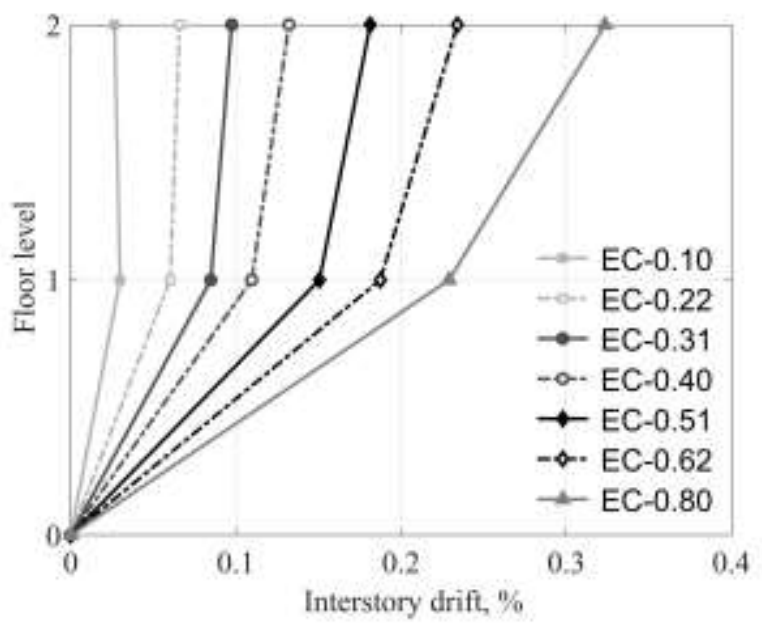

(b)

Fig. 11 Inter-story drift angles of the Model-2 for each test of El Centro motion: (a) X direction; (b) Y direction

The maximum inter-story drift angles of the two models with the increase of the motion intensity are shown in Fig. 12, in which the horizontal dotted green line represents the inter-story drift angle limit for reinforced concrete shear wall structure in elastic stage according to the Code for seismic design of buildings [39], which is equal to $0.1 \%$. It can be seen that the inter-story drift angles of the Model-2 increased significantly according to the ground motion intensity level, while the inter-story drift angles of the Model-1 changed slightly, and the maximum inter-story drift angle of the Model-2 was greater than that of the Model-1. This is attributed to the significant improvement of the box action of the Model-1 induced by the fixed-fixed end conditions between the connecting columns and the foundation. With the increasing of earthquake input, the maximum inter-storey drift angle increased linearly in general, while the inter-story drift angles for the artificial and Kobe waves increased nonlinearly at later cases in the Model-2. Under the excitation of $0.22 \mathrm{~g}$ (7-degree earthquake), the maximum inter-story drift angle in the X direction and Y direction of the Model-1 were $1 / 2580$ and 1/1842, respectively, and the Model-2 were 1/3018 and 1/3343, respectively, which were far less than the corresponding inter-story drift angle limits of $1 / 1000$ and 1/120 for RC shear wall structure in elastic and plastic stages, respectively. Under the loading of $0.62 \mathrm{~g}$ (9-degree rare earthquake), the maximum inter-story drift angles of 1/1201 and 1/781 for the Model-1 in the X and Y directions, respectively, and of 1/361 and 1/212 for the Model-2, respectively, were also far less than the limit value of $1 / 100$ for the elastic-plastic inter-story drift. The maximum interstory drift angles of the Model-1 were 1/2238, 1/1794 and 1/1499, respectively, when the model was loaded at 8-degree $(0.40 \mathrm{~g}), 8.5$-degree $(0.51 \mathrm{~g})$ and 9-degree $(0.62 \mathrm{~g})$ of rare earthquakes, and 1/560, 1/529 and 1/389 of the Model-2, respectively. According to the definition of the damage state of shear wall structure in the Classification of earthquake damage to buildings and special structures [40] and the Code for design of concrete structures [36], the Model-1 was basically in the damage state of no damage. Model-2 was in a state of slight damage under the 8 and 8.5 degrees of rare earthquakes and in the state of moderate damage under the 9-degree of rare earthquake. This indicated that both the Model-1 and the Model-2 exhibited excellent resistance to deformation and performed satisfactorily as it withstood a series of tests with strong intensities exceeding the maximum considered earthquake. 

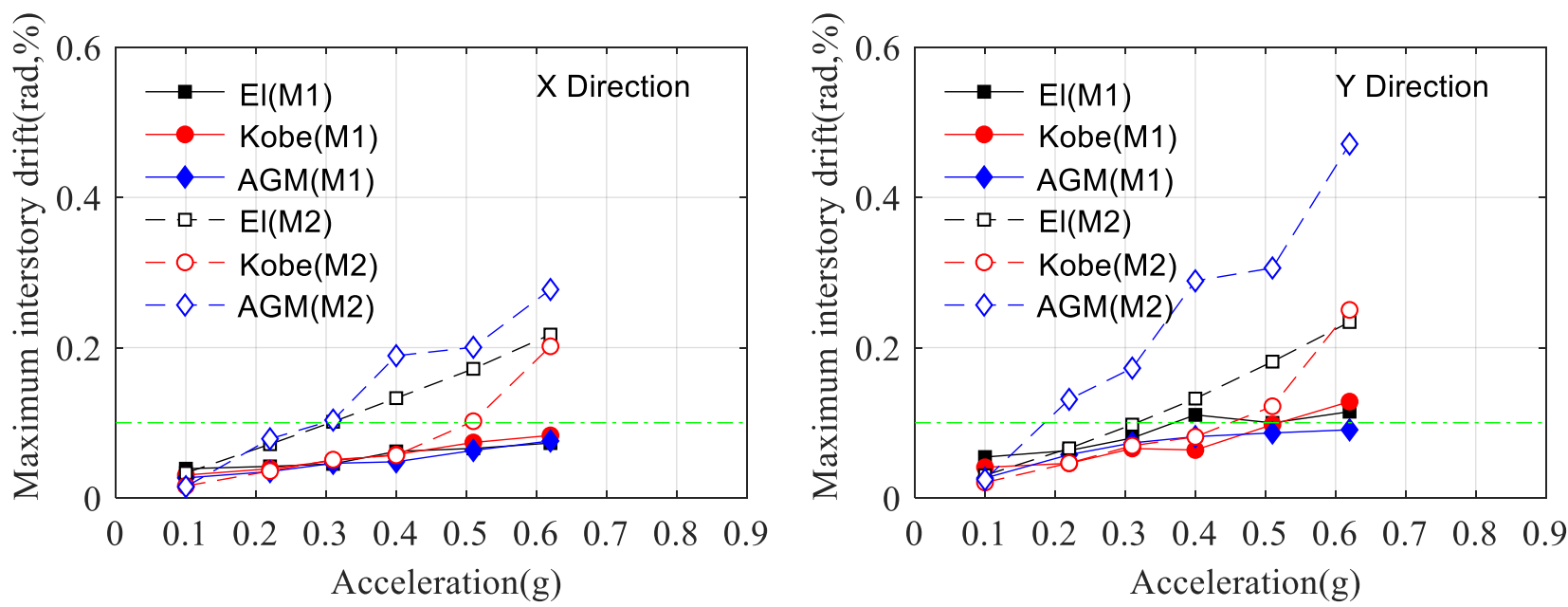

(a) Maximum inter-story drift angles in X direction (b) Maximum inter-story drift angles in Y direction

Fig. 12 Maximum inter-story drift angles of the two models

\subsection{Global Hysteresis}

The test building can be simplified into a multi-degree-of-freedom (MDOF) system, and the total seismic weight considered for the model structure was $576.2 \mathrm{kN}$, with $354.0 \mathrm{kN}$ and $222.2 \mathrm{kN}$ at the first and second levels, respectively. Newton's second law was used to calculate the inertial force of each story by using the values of acceleration time histories recorded on both floors at the center of the diaphragm. The shear force for each story was then calculated accordingly, and the base shear was normalized with respect to the seismic weight of the test building, which was called base shear coefficient (BSC). The hysteretic responses of the Model-2 under El Centro motions is presented in Fig. 13 in terms of the base shear versus the roof drift in the X direction. As shown in the figure, the first slight nonlinearity in the hysteretic response was observed during testing under EC-0.31, associated with the occurrence of spread diagonal cracks at the edges of the openings on the longitudinal walls. During the test at EC-0.62, a significant nonlinear behaviour was observed associated with extended damage to the bolt joints and slight reduction of pre-tension in the high strength bolts, highlighted by the enlargement of the hysteresis loops. The maximum values of BSC in the negative and positive direction were equal to 0.91 and 0.57 , respectively. The difference in the resistances in the two directions can be attributed to the negative "spike" of the applied ground motion. No indication of strength degradation confirms the absence of observable structural failures in the model structure, since the strength demand was far less than the utmost bearing capacity. In a word, the model structure possessed the ability to resist the maximum considered earthquake of the seismic design intensity $9(\mathrm{PGA}=0.62 \mathrm{~g})$.

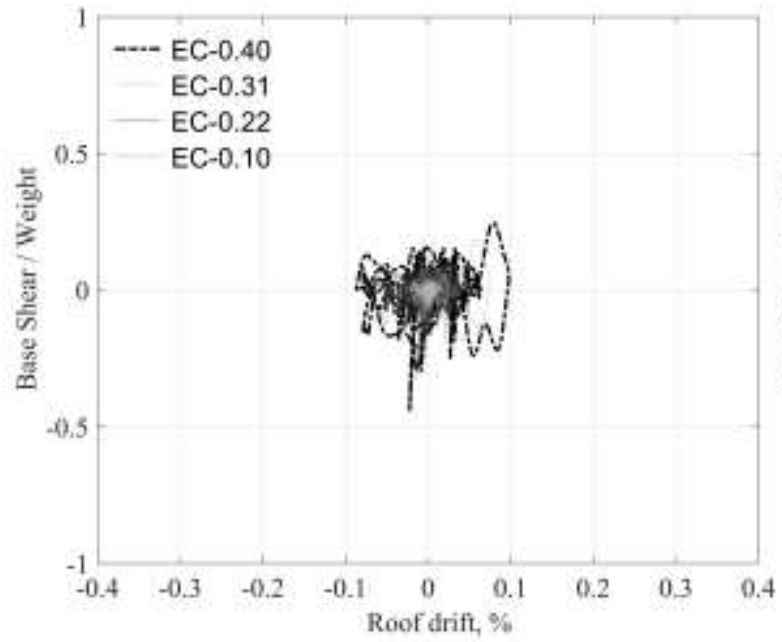

(a)

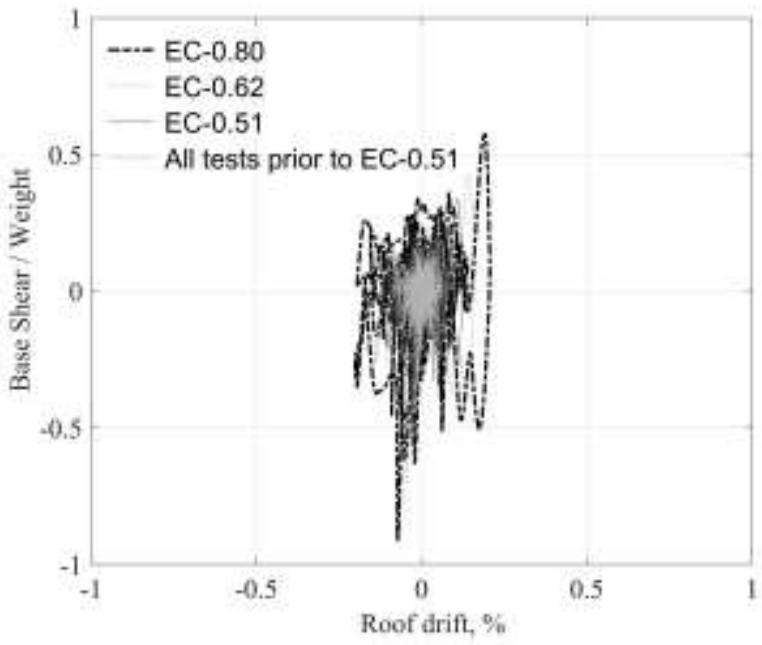

(b)

Fig. 13 Base shear versus roof drift of the Model-2 in the X direction: (a) base shear versus roof drift for selected tests; (b) base shear versus roof drift for the last three tests 
To simplify the design calculations, the model structure (i.e. the MDOF system mentioned above) could be substituted by a SDOF system with the same fundamental period according to the equivalent base shear method in GB50011 [39], and the design base shear forces in both systems were equal. Thus, the design base shear force of the model structure was calculated by Equation (1), and then the theoretical lateral seismic force for each story was calculated accordingly Equation (2).

$$
\begin{gathered}
F_{\mathrm{E}}=0.85 \alpha_{\max } G_{\mathrm{E}} \\
F_{i}=\frac{G_{i} H_{i}}{\sum_{j=1}^{2} G_{j} H_{j}} F_{\mathrm{E}}
\end{gathered}
$$

where $F_{\mathrm{E}}$ and $G_{\mathrm{E}}$ are the design base shear and the total seismic weight of the test building, respectively. $\alpha_{\max }$ is the seismic influence coefficient in different seismic design intensity. $F_{i}, G_{i}$, and $H_{i}$ are the theoretical lateral seismic force, the seismic weight, and story height in the $i$-th floor level, respectively.

Fig.14 presents the normalized peak base shear forces of two models measured in each testing stages, including the ratio of the design base shear force to the total seismic weight (i.e. $0.85 \alpha_{\max }$ ) in different seismic design intensity. The base shear force is normalized by the seismic weight of the model structure, and $0.85 \alpha_{\max }$ is obtained from GB50011 [39]. It can note that the normalized peak base shear forces of two models were always smaller than the ratio of the design base shear force to the total seismic weight (i.e. $0.85 \alpha_{\max }$ ) in each seismic design intensity, which indicates that the feasibility of the equivalent base shear method in GB50011 for estimating the design base shear force of the model structure. Moreover, it also can be seen from Fig. 22 that the structure developed the incremental base shear force as the intensity level of ground motions increased. The almost linear increase of the peak base shear force indicate that no severe damage and strength degradation occurred in the model structure throughout the shaking table test. Combing with aforementioned test observations, it can be concluded that the model structure was far from reaching its base-shear capacity and the structure was not in danger of failing.

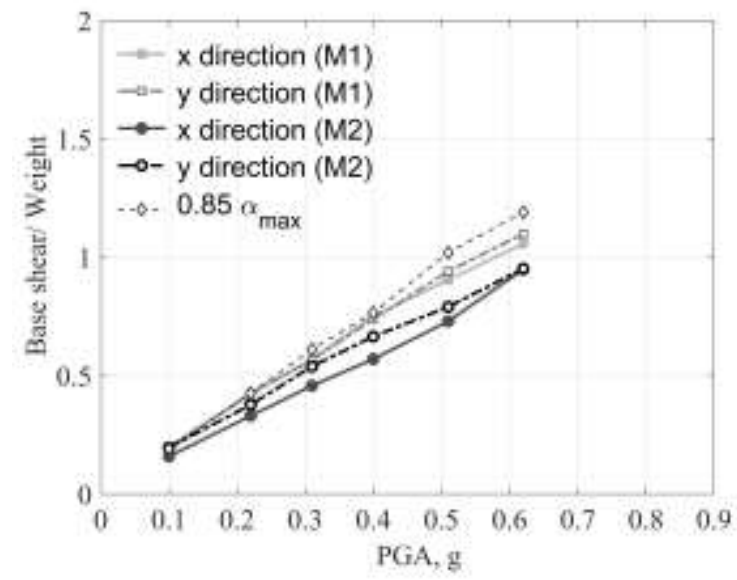

Fig. 14 Normalized peak base shear of the Model-1 and the Model-2 measured in each testing stages

The distribution of peak shear force normalized by the seismic weight of the model structure in each story is shown in Fig. 15 (a) for each stage under the El Centro ground motion. The distribution of the inertia forces over the height permits the determination of the effective height of the resultant lateral force as shown in Fig. 15 (b), which is calculated for each test as the ratio of the peak overturning moment at the base to the peak base shear. The theoretical values of effective height obtained by using the theoretical lateral seismic force calculated from Equation (1) are also plotted in Fig. 15 (b). It can be seen that the effective heights were mainly in good agreement with the theoretical values throughout all the stages of shaking table test, and close to the height of the resultant force corresponding to a uniform load distribution. This indicates that the lateral seismic force of the model structure in each story can be estimated by the equivalent base shear method in GB50011 [39] and its distribution can be considered uniform. 


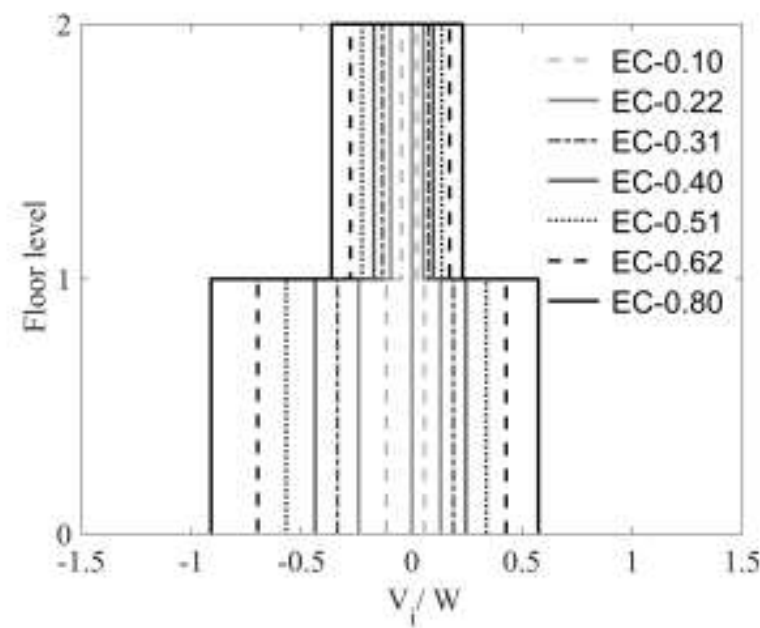

(a)

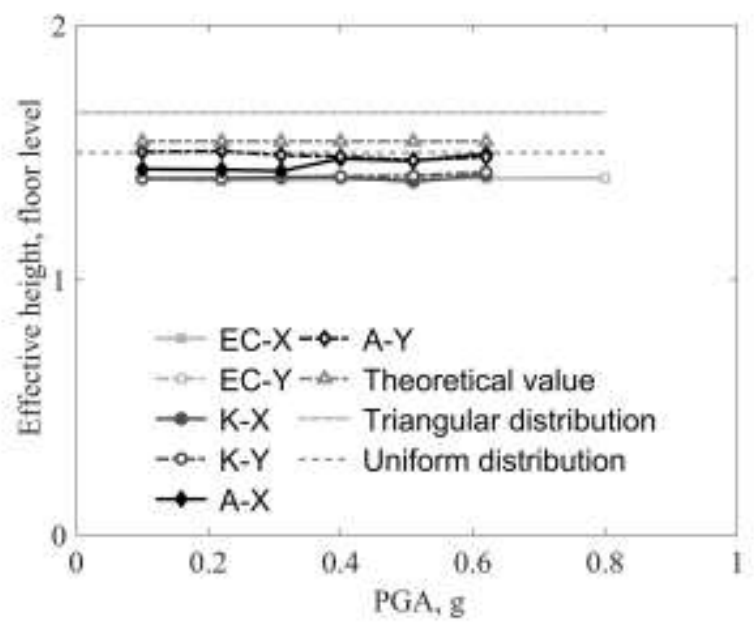

(b)

Fig. 15 Story shear forces and effective height of lateral-force resultant of the Model-2: (a) normalized peak story shear forces in the Y direction; (b) effective height of resultant lateral force

\section{Discussion and conclusions}

A novel bolt-connected PCSWPS system is proposed in this paper. The seismic performance of the structural system was investigated by shake table testing of a full-scale two-story precast concrete composite wall panel structure. The performance of the new bolt connection structure proposed in this paper is compared with the precast structures proposed by Brunesi et al. [18] and Guo et al. [19]. Brunesi et al. [18] presented a connection method in which the wall and floor slab were connected by felts, mortar joints and mechanical steel anchors and they studied the performance in a full-scale two-story wall-slab-wall structure. A new structure with a dry connection was presented by Guo et al. [19], in which embedded connecting steel plates and high strength bolts were used. In this system, the steel plates were preembedded in the concrete structure. A shaking table test of a $1 / 2$ scaled three-story model was conducted in this research. For the wet connection method proposed by Brunesi et al. [18], cracks were observed at the base of the wall when the specimen was subjected to a $0.45 \mathrm{~g}$ input motion, and the cracks spread all over the structure and also a permanent displacement of about $10 \mathrm{~mm}$ in certain parts of the specimen occurred under the excitation of $0.6 \mathrm{~g}$. The near collapse of the structure was found at the second excitation of $0.6 \mathrm{~g}$. The joint connection was the weak part of this system. For Guo et al., [19], under an excitation of $0.14 \mathrm{~g}$, the horizontal joint of the bolt connection for the wall-to-wall was loose, and the first and second stories slight slid. The spalling of concrete at the interface of the wall and floor occurred because of the sliding at an excitation of $0.3 \mathrm{~g}$. Cracks on the exterior walls were observed and propagated when the test model was loaded at $0.60 \mathrm{~g}$. A few anchored rods showed slight residual deformation. The failure mode of the structure followed the order of bolt loosening, sliding and dislocation of adjacent wall panels, and cracking of structural components. Compared with the experimental results of these two structures, in the structural system proposed in this paper, there were only a small number of cracks at the grouting layers at the bottoms of the columns in the first floor in Model-1, and there were no visible cracks in the wall panel, floor slab and horizontal and vertical joints after $0.62 \mathrm{~g}$ earthquake excitation. Model-1 was still in good condition. However, at the same peak acceleration, the system proposed by Brunesi et al. [18] showed a near collapse of the structure because of failure of the steel connectors joining the transverse and longitudinal walls, and structural cracks appeared in the exterior wall in the structural system proposed by Guo et al. [19]. Obviously, compared with these two structural systems, the high strength bolt connection in this paper was not the weak part in the system and had a better seismic performance. The precast wall panel system proposed in this paper also has better seismic performance, and the following conclusions are drawn.

The experimental results indicated that the test building works in an integrity system even under strong earthquake excitation, and the bolt joints are valid to connect all the components. No slippages occurred at the horizontal and vertical joints, and bolted connectors including connecting steel plates and high-strength bolts were intact during the whole testing. The structural damage was mainly concentrated on the wall openings and the bottoms of walls and columns, mainly characterized by concrete cracking, demonstrating the effectiveness of the connection design. The deformation of the model structure was dominated by bending and shearing of the precast concrete sandwiched insulated wall panels rather than rocking or base sliding. The damage and deformation mechanism of the boltassembled wall system were similar with those of an in-situ cast structure.

The bolt-assembled precast concrete wall system exhibited excellent resistance to deformation and performed satisfactorily under the PGA of up to $0.8 \mathrm{~g}$. The peak base shear force and the peak inter-story drift angle met the 
seismic demands specified in the Chinese codes. The equivalent base shear method in the Chinese code is suitable for estimating the seismic demands of the bolt-assembled precast concrete wall system including design base shear force and story shear force. With the advantages of high degree of industrialization, simple construction, rapid construction speed and high economic benefits, this wall system is suitable for low-rise residential building in the vast rural areas of China, especially in zones of high intensity.

\section{Acknowledgements}

The authors wish to gratefully acknowledge the financial support of the National key Research and Development Program of China (Grant No.: 2018YFD1100903-02). The authors are also grateful to the technicians in the laboratory for helping to make the models.

\section{References}

[1] Pavese A, Bournas DA. Experimental assessment of the seismic performance of a prefabricated concrete structural wall system. Engineering Structures, 2011, 33(6): 2049-2062.

[2] Todut C, Dan D, Stoian V. Theoretical and experimental study on precast reinforced concrete wall panels subjected to shear force. Engineering Structures, 2014, 80: 323-338.

[3] Zhi Q, Guo Z X, Xiao Q D, Yuan F, Song J R. Quasi-static test and strut-and-tie modeling of precast concrete shear walls with grouted lap-spliced connections. Construction and Building Materials, 2017, 150: 190-203.

[4] Qin C G, Bai G L, Xu Y Z, Su N F, Wu, T, Li Z L, Sun Y Z. Shaking table test on seismic responses of a monolithic precast concrete shear wall structure. KSCE Journal of Civil Engineering, 2018, 22(10): 3903-3918.

[5] Han W L, Zhao Z Z, Qian J R. Global experimental response of a three-story, full-scale precast concrete shear wall structure with reinforcing bars spliced by grouted couplers. PCI Journal, 2019, 64(1), 65-80.

[6] Perez F J, Sause R, Pessiki S. Analytical and experimental lateral load behavior of unbonded posttensioned precast concrete walls. Journal of Structural Engineering, 2007, 133(11): 1531-1540.

[7] Erkmen B, Schultz A E. Self-centering behavior of unbonded, post-tensioned precast concrete shear walls." Journal of Earthquake Engineering, 2009, 13(7): 1047-1064.

[8] Sritharan S, Aaleti S, Henry R S, Liu K, Tsai K. Precast concrete wall with end columns (PreWEC) for earthquake resistant design. Earthquake Engineering \& Structural Dynamics, 2015, 44(12): 2075-2092.

[9] Henry R S, Sritharan S, Ingham J M. Finite element analysis of the PreWEC self-centering concrete wall system. Engineering Structures, 2016, 115: 28-41.

[10] Nazari M, Sritharan S, Aaleti S. Single precast concrete rocking walls as earthquake force-resisting elements. Earthquake Engineering \& Structural Dynamics, 2017, 46(5): 753-769.

[11] Twigden K M, Henry R S. Shake table testing of unbonded post-tensioned concrete walls with and without additional energy dissipation. Soil Dynamics and Earthquake Engineering, 2019, 119: 375-389.

[12] Twigden K M, Sritharan S, Henry R S. Cyclic testing of unbonded post-tensioned concrete wall systems with and without supplemental damping. Engineering Structures, 2017, 140: 406-420.

[13] El Semelawy, M, El Damatty A, Soliman A M. Novel anchor-jointed precast shear wall: testing and validation. Structures and Buildings, 2014, 168(SB4): 263-274.

[14] Brunesi E, Nascimbene R. Experimental and numerical investigation of the seismic response of precast wall connections. Bulletin of Earthquake Engineering, 2017, 15(12): 5511-5550.

[15] Psycharis I N, Kalyviotis I M, Mouzakis H P. Experimental investigation of the response of precast concrete cladding panels with integrated connections under monotonic and cyclic loading. Engineering Structures, 2018, 159: 75-88.

[16] Brunesi E, Peloso S, Pinho R, Nascimbene R. Cyclic tensile testing of a three-way panel connection for precast wallslab-wall structures. Structural Concrete, 2019a, 20 (4): 1307-1315.

[17] Guo W, Zhai Z P, Yu Z W, Chen F, Gong Y Z, Tan T. Experimental and numerical analysis of the bolt connections in a low-rise precast wall panel structure system. Advances in Civil Engineering, 2019a: 1-22.

[18] Brunesi E, Peloso S, Pinho R, Nascimbene R. Shake-table testing of a full-scale two-story precast wall-slab-wall structure. Earthquake Spectra, 2019b, 35(4): 1583-1609.

[19] Guo W, Zhai Z P, Cui Y, Yu Z W, Wu X L. Seismic performance assessment of low-rise precast wall panel structure with bolt connections. Engineering Structures, 2019b, 181: 562-578.

[20] Psycharis I N, Kalyviotis I M, Mouzakis H P. Shake table tests on the dynamic response of cladding panels with fixed connections. Journal of Earthquake Engineering, 2020:1-26.

[21] Chen W, Xiong F, Lu Y, Chen J, Feng B, Zhao P, Malla P. Experimental investigation of the seismic performance of a novel bolt-assembled precast panel building structure. Journal of Earthquake and Tsunami, 2019, 13(3\&4): $2966-2975$.

[22] Cai G C, Xiong F, Xu Y, Si Larbi A, Lu Y, Yoshizawa M. A demountable connection for low-rise precast concrete structures with DfD for construction sustainability-a preliminary test under cyclic loads. Sustainability, 2019, 11(13): 1-16.

[23] Xiong F, Malla P, Cai G C, Si Larbi A, Zhong Y C, Tufail R F, Chen W, Huang W. Numerical analysis of precast concrete shear walls with horizontal bolted joints under seismic loads. Journal of Earthquake Engineering, 2020a: 1-24.

[24] Xiong F, Zhao F C, Cai G C, Chen J, Si Larbi A. Seismic performance of a bolt-assembled precast panel building with DfD: a quasi-static test and discussion on existing design codes. Journal of Earthquake Engineering, 2021: 1-20. 
[25] Malla P, Xiong, F, Cai G C, Xu, Y, Larbi A S, Chen W. Numerical study on the behaviour of vertical bolted joints for precast concrete wall-based low-rise buildings. Journal of Building Engineering, 2021, 33: 101529.

[26] Lu Y, Chen W, Xiong F, Yan H Q, Ge Q, Zhao F C. Seismic performance of a full-scale two-story bolt-connected precast concrete composite wall panel building tested on a shake table. Journal of Structural Engineering, 2021: 1-13.

[27] Sun J, Qiu H X, Yang Y, Lu B. Experimental and analytical studies on the deformability of a precast RC shear wall involving bolted connections. Science China Technological Sciences, 2015, 58(8): 1439-1448.

[28] Sun J, Qiu H X, Lu Y. Experimental study and associated numerical simulation of horizontally connected precast shear wall assembly. The Structural Design of Tall and Special Buildings, 2016, 25(13): 659-678.

[29] Jiang H B, Qiu H X, Sun J, Yang Y. Behavior of steel-concrete composite bolted connector in precast reinforced concrete shear wall. Advances in Structural Engineering, 2019, 22(12): 2572-2582.

[30] Sun J, Qiu H X, Jiang H B. Experimental study and associated mechanism analysis of horizontal bolted connections involved in a precast concrete shear wall system. Structural Concrete, 2019a, 20(1): 282-295.

[31] Sun J, Qiu H X, Jiang H B. Lateral load behaviour of a rectangular precast shear wall involving vertical bolted connections. Advances in Structural Engineering, 2019b, 22(5): 1211-1224.

[32] Sun J, Qiu H X, Lu Y, Jiang H B. Experimental study of lateral load behavior of H-shaped precast reinforced concrete shear walls with bolted steel connections. The Structural Design of Tall and Special Buildings, 2019c: e1663.

[33] Wang W, Li A Q, Wang X X. Seismic performance of precast concrete shear wall structure with improved assembly horizontal wall connections. Bulletin of Earthquake Engineering, 2018, 16(9), 4133-4158.

[34] GB 5009-2010. Load code for the design of building structures. Beijing: Ministry of Housing and Urban-Rural Development of the People's of China, 2010.

[35] GB50017-2017. Standard for design of steel structures. Beijing: Ministry of Housing and Urban-Rural Development of the People's of China, 2017.

[36] GB50010-2010. Code for design of concrete structures (2015 version). Beijing: Ministry of Housing and Urban-Rural Development of the People's of China, 2015.

[37] JGJ1-2014. Technical specification for precast concrete structures. Beijing: Ministry of Housing and Urban-Rural Development of the People's of China, 2014.

[38] CECS604-2019. Technical specification for multi-story precast concrete structures. Beijing: China Academy of Building Research, 2019.

[39] GB 50011-2010. Code for seismic design of buildings. Beijing: Ministry of Housing and Urban-Rural Development of the People's of China, 2015.

[40] GB/T 24335-2009. Classification of earthquake damage to buildings and special structures. Beijing: China Earthquake Administration, 2009. 